\title{
Cellular senescence in the aging retina and developments of senotherapies for age- related macular degeneration
}

\author{
Keng Siang Lee ${ }^{1 \dagger}$, Shuxiao Lin ${ }^{2 \dagger}$, David A. Copland ${ }^{1}$, Andrew D. Dick ${ }^{1,3,4^{*}}$ and Jian Liu ${ }^{1 *}$ (D)
}

\begin{abstract}
Age-related macular degeneration (AMD), a degenerative disease in the central macula area of the neuroretina and the supporting retinal pigment epithelium, is the most common cause of vision loss in the elderly. Although advances have been made, treatment to prevent the progressive degeneration is lacking. Besides the association of innate immune pathway genes with AMD susceptibility, environmental stress- and cellular senescence-induced alterations in pathways such as metabolic functions and inflammatory responses are also implicated in the pathophysiology of AMD. Cellular senescence is an adaptive cell process in response to noxious stimuli in both mitotic and postmitotic cells, activated by tumor suppressor proteins and prosecuted via an inflammatory secretome. In addition to physiological roles in embryogenesis and tissue regeneration, cellular senescence is augmented with age and contributes to a variety of age-related chronic conditions. Accumulation of senescent cells accompanied by an impairment in the immune-mediated elimination mechanisms results in increased frequency of senescent cells, termed "chronic" senescence. Age-associated senescent cells exhibit abnormal metabolism, increased generation of reactive oxygen species, and a heightened senescence-associated secretory phenotype that nurture a proinflammatory milieu detrimental to neighboring cells. Senescent changes in various retinal and choroidal tissue cells including the retinal pigment epithelium, microglia, neurons, and endothelial cells, contemporaneous with systemic immune aging in both innate and adaptive cells, have emerged as important contributors to the onset and development of AMD. The repertoire of senotherapeutic strategies such as senolytics, senomorphics, cell cycle regulation, and restoring cell homeostasis targeted both at tissue and systemic levels is expanding with the potential to treat a spectrum of age-related diseases, including AMD.
\end{abstract}

Keywords: Macular degeneration, Cellular senescence, SASP, Immune aging, Retinal pigment epithelium, Microglia, Neuron

\section{Background}

The steady increase in life expectancy and the aging population has presented us with a new challenge: agerelated diseases. Age-related macular degeneration (AMD), a degenerative disease affecting the central area of the neuroretina (macula) and supporting retinal pigment epithelium, is the leading cause of registered

\footnotetext{
*Correspondence: a.dick@bristol.ac.uk; a.dick@ucl.ac.uk; jian.liu@bristol.ac.uk ${ }^{\dagger}$ Keng Siang Lee and Shuxiao Lin contributed equally to this work. 'Bristol Medical School, Translational Health Sciences, University of Bristol, Bristol BS8 1TD, UK

Full list of author information is available at the end of the article
}

blindness in western countries in those aged 65 and over $[1,2]$. It is steadily becoming a major public health issue as the global AMD burden is projected to reach 288 million people by $2040[1,2]$. In the USA, approximately 11 million people are affected by AMD, a prevalence that is similar to that of all invasive cancers combined, and over double of that of Alzheimer's disease (AD) [1]. Visual loss significantly affects activities of daily living, and people fear losing sight as much as developing cancer or dementia [3]. The global cost of visual impairment due to AMD alone is substantial, estimated to be US\$343

C C The Author(s). 2021 Open Access This article is licensed under a Creative Commons Attribution 4.0 International License, which permits use, sharing, adaptation, distribution and reproduction in any medium or format, as long as you give appropriate credit to the original author(s) and the source, provide a link to the Creative Commons licence, and indicate if changes were made. The images or other third party material in this article are included in the article's Creative Commons licence, unless indicated otherwise in a credit line to the material. If material is not included in the article's Creative Commons licence and your intended use is not permitted by statutory regulation or exceeds the permitted use, you will need to obtain permission directly from the copyright holder. To view a copy of this licence, visit http://creativecommons.org/licenses/by/4.0/ The Creative Commons Public Domain Dedication waiver (http://creativecommons.org/publicdomain/zero/1.0/) applies to the data made available in this article, unless otherwise stated in a credit line to the data. 
billion including $74 \%$ in direct healthcare costs (AMD Alliance International).

AMD is a progressive, polygenic, and multifactorial disease with complex etiology. Although age remains the primary risk factor for AMD, the interplays of susceptible genes associated with complement activation, lipid metabolism, cholesterol transport, receptor-mediated endocytosis, and extracellular matrix organization, alongside environmental risk factors, such as smoking, diet, obesity, sunlight exposure, alcohol consumption, and cardiovascular disease, increase the risk of developing or are associated with enhanced severity of AMD [4-6]. Clinically, early AMD can be characterized by the deposition of lipoproteinaceous drusen at the sub-retinal pigment epithelium (RPE) accompanied by pigmentary abnormalities in the RPE, which progresses into two late forms, dry (atrophic) and wet (neovascular) [1, 7]. Dry AMD is a slow progressive deterioration in visual function characterized by insidious atrophy of the RPE and rod and cone photoreceptors $[1,2]$. Ten to $15 \%$ of patients with dry AMD progress to the wet form, distinguished by the generation of an abnormal choroidal neovascular membrane into the macula (a process termed as choroidal neovascularization or $\mathrm{CNV}$ ), which is prone to leakage or hemorrhage beneath the retina leading to retinal scarring and sudden vision loss $[1,2]$. Current anti-vascular endothelial growth factor (VEGF) therapies have revolutionized treatment for the inhibition of the pathological neoangiogenesis of wet AMD (advanced disease), however, many years after the progression of degeneration has ensued $[8,9]$. Due to the lack of treatment to counter the degenerative processes per se, a substantial proportion of AMD eventually leads to severe visual impairment or blindness [1, 7].

Despite our increased understanding, active therapeutic intervention remains of limited benefit for patients with AMD. The Age-Related Eye Disease Studies (AREDS/AREDS2) assessed the effects of nutritional supplements on the course of AMD and found that taking antioxidant nutrient formula (vitamin $\mathrm{C}$, vitamin $\mathrm{E}$, lutein, and zeaxanthin) in combination with zinc can reduce the progression from intermediate to advanced AMD by $25 \%$, however, with no effect in preventing early AMD $[10,11]$. Current clinical trials investigating drugs, biologics, and small molecules to target the biological pathways in AMD, such as oxidative stress, visual cycle inhibition, complement activation, retinal/choroidal blood flow, amyloid beta (A $\beta)$, and lipid accumulation, have yet to generate tractable therapies $[12,13]$.

The eye is an ideal organ for gene therapy because of the relative ease of access and compartmentalization, relative immune privilege, and small size reducing the viral load required. Unsurprisingly, the use of ocular gene therapy has been successful in a variety of ocular diseases $[14,15]$. These include gene therapy trials for inherited retinal degenerations, such as Leber congenital amaurosis (LCA), retinitis pigmentosa, choroideremia, and X-linked retinoschisis (XLRS) [14, 16, 17]. As reported, seven gene therapy trials have been developed to treat wet AMD via transgene infections to continuously express antiangiogenic proteins, such as anti-VEGF Fab, soluble fms-like tyrosine kinase-1 (sFlt-1), and endostatin $[18,19]$. For dry AMD, there are currently two ongoing gene therapy trials, including GT005 (phase I) that induces ocular complement factor I (CFI) expression [20] and HMR59 (AAVCAGsCD59, phase I) that expresses C59 to prevent formation of the membrane attack complex (MAC) [21].

The goal to prevent the progressive loss of RPE and photoreceptors that characterize the macular degeneration relies on our understanding of key events defining the transition from normal aging to AMD. Altered pathways and processes of cellular metabolism, oxidative stress, cellular senescence, and associated inflammatory responses are all potential contributory or causative factors disrupting tissue homeostasis [22-24]. Cellular senescence is one of the adaptive cell responses induced by different types of stress and accompanying normal aging [23]. Disproportionate senescent changes in tissueresident cells or systemic immune cells exacerbate the adverse effects of aging, which clinically lead to different chronic disorders, including AMD [25-27]. This review strives to provide current insights of cellular senescence in retinal aging and development of AMD, over and above a perspective of senotherapeutic strategies against AMD to achieve a healthy aging with vision.

\section{Senescence is an adaptive and programmed cellular response with distinct characteristics}

The concept of senescence, the condition or process of gradual deterioration with age, was formulated by Peter Medawar in the 1950s [28]. During the early 1960s, Leonard Hayflick and Paul Moorhead further ascribed the senescence at the cellular level as a state of irreversible cessation of cell division when the cells entered the end of their replicative lifespan but remained viable [29]. Cellular senescence is a cell-intrinsic and adaptive response to a variety of exogenous and endogenous stimuli, originally characterized by a stable cell cycle arrest (G1 arrest) only in mitotic cells [30,31]. Recent experimental and clinical evidence reveals senescence in postmitotic and rare mitotic cells, such as the terminally differentiated neurons of the central nervous system (CNS), cardiomyocytes, osteocytes, and adipocytes [3234]. Regarded as a multistep process, the initiation and induction of senescence in the cells requires the activation of tumor suppressors involved in the p53/p21 ${ }^{\mathrm{CIP} 1}$ and $\mathrm{p} 16^{\mathrm{INK} 4 \mathrm{~A}} /$ retinoblastoma protein (RB) pathways [31, 
35]. Another key feature of cellular senescence is the senescence-associated secretory phenotype (SASP) wherein the senescent cells release a host of proinflammatory mediators through pathways dependent on p38 MAPK, NF-kB, Notch, and/or mTOR signaling [36-38]. Cellular senescence is operative both physiologically and pathologically, ranging from embryonic development, tissue remodeling, wound repair, cancer, and aging [30-32].

Similar to apoptosis and autophagy, cellular senescence is a distinct cell response to intrinsic cues including telomere shortening, metabolic and proteostatic dysfunction, as well as extrinsic factors such as increased oxidative stress incited by UV radiation, cigarette smoking or microbial infections, and chronic stress from inflammation [39]. Cellular senescence is also attributed to other forms of genotoxic stress, mitogens or inflammatory cytokines, that culminate in the activation of the p53 tumor suppressor and/or the cyclin-dependent kinase inhibitor $\mathrm{p} 16^{\mathrm{INK} 4 \mathrm{~A}}$ [39]. Cellular senescence can be classified into three types: replicative senescence (RS), stress-induced premature senescence (SIPS), and developmentally programmed senescence (DPS) [31]. RS is mainly induced by telomere shortening or dysfunction, whereas SIPS can be telomere independent [37].

A physiological role of programmed cellular senescence is to maintain normal tissue homeostasis including tissue repair and tumor suppression [35, 40, 41]. Cells including myofibroblasts enter acute senescence to reduce fibrosis [42, 43], and with defective senescence (e.g., deficiency in p53, p16 ${ }^{\mathrm{INK} 4 \mathrm{~A}}$, or TRE-shp53), excessive fibrosis ensues in the liver [42]. When there is expression of transcription factors OCT4, SOX2, KLF4, and MYC (OSKM), reprogramming of a small population of adult-differentiated cells into the pluripotent stem cells occurs with an induction of senescence of many other cells. The OSKM-driven senescent cells promote cell reprogramming that facilitates tissue repair [41]. Similarly in tumors, oncogene-induced senescence has been regarded as an intrinsic mechanism for tumor suppression and immune surveillance [40]. Loss of key senescence-inducing genes $-p 53, p 16^{I N K 4 A}$, or $p 19^{A R F}-$ causes an inactivation of the senescence pathways favoring malignant transformation [44].

Senescent cells undergo distinctive and profound morphological and functional alterations in chromatin, metabolism and secretome, both in vitro and in vivo [31, $35,45]$. These include (1) altered cellular morphology (often enlarged, flat, multivacuolated, and multinucleated); (2) increased senescence-associated $\beta$-galactosidase (SA- $\beta$-Gal) activity; (3) the accumulation of DNA damage foci including double-strand breaks (DSBs); (4) the accumulation of chromatin modifications, such as senescence-associated heterochromatic foci (SAHF) that is enriched in a transcription-silencing histone $\mathrm{H} 2 \mathrm{~A}$ variant (macroH2A); (5) chromosomal instability associated with the reduction in lamin $\mathrm{B} 1$ and the release of high mobility group box 1 protein (HMGB1); (6) altered mitochondrial metabolism with elevated glycolytic rate; (7) a SASP phenotype producing cytokines, growth factors, proteases, and lipids, which constitutes a senescence-specific micro-environment influencing surrounding cells $[46,47]$; and (8) the expression of senescence marker proteins (i.e., p38 MAPK, p53, p21 ${ }^{\mathrm{CIP} 1}$, $\mathrm{p} 16^{\mathrm{INK} 4 \mathrm{~A}}, \mathrm{RB}$, and cyclin-dependent kinases (CDKs)) [37]. These characteristics might reflect either the causal factors or consequences of senescence. These nonexclusive features could also be the by-products of physiological changes in non-replicating cells or nonsenescent cells $[37,48]$. A robust and unequivocal panel of markers of the senescence has to be determined in a cell population-dependent context [37, 48]. Moreover, subsets of senescent cells with phenotypic and functional heterogeneity are recognized and must be considered for therapeutic targeting [49].

\section{Cell senescence is an important driver for age- related diseases including AMD}

As the protective role of senescence relies on acute response to adverse molecular damages combined with the timely elimination of senescent cells via cell death or immune actions, overproduction of senescent cells or impairment of the removal mechanism will lead to a detrimental hoarding of senescent cells, termed as "chronic" senescence [43, 50]. Age-associated changes in the cells, such as telomere erosion, DNA lesions, ROS production, and metabolic disturbance are potent triggers that may induce senescence. The persistent accumulation of senescent cells due to chronic stress is a result of aging and a major driver of age-related illnesses [45]. Examples are pulmonary fibrosis, diabetic pancreas, osteoarthritis, atherosclerosis, AD, and Parkinson's disease (PD), as well as ocular diseases such as glaucoma and cataracts [51]. The senescent cell burden in the brain induces inflammation and alters iron metabolism, changes associated with neurodegeneration and cognitive decline in an $\mathrm{AD}$ model. Conversely, elimination of senescent cells mitigates the disease severity [52]. As in other adult tissues, the senescence program may be elicited in the eye by various exogenous and endogenous factors such as oxidative stress, metabolic disturbance, nutrient and growth factor signals, telomere dysfunction, and DNA damage [53-55]. Other stimulants including autophagy dysfunction and abnormal inflammatory response also play a role in activating cellular senescence (Fig. 1).

Cumulative evidence has demonstrated senescent RPE cells in human AMD donor eyes and old non-human primate eyes [56-59]. In addition to RPE, retinal 


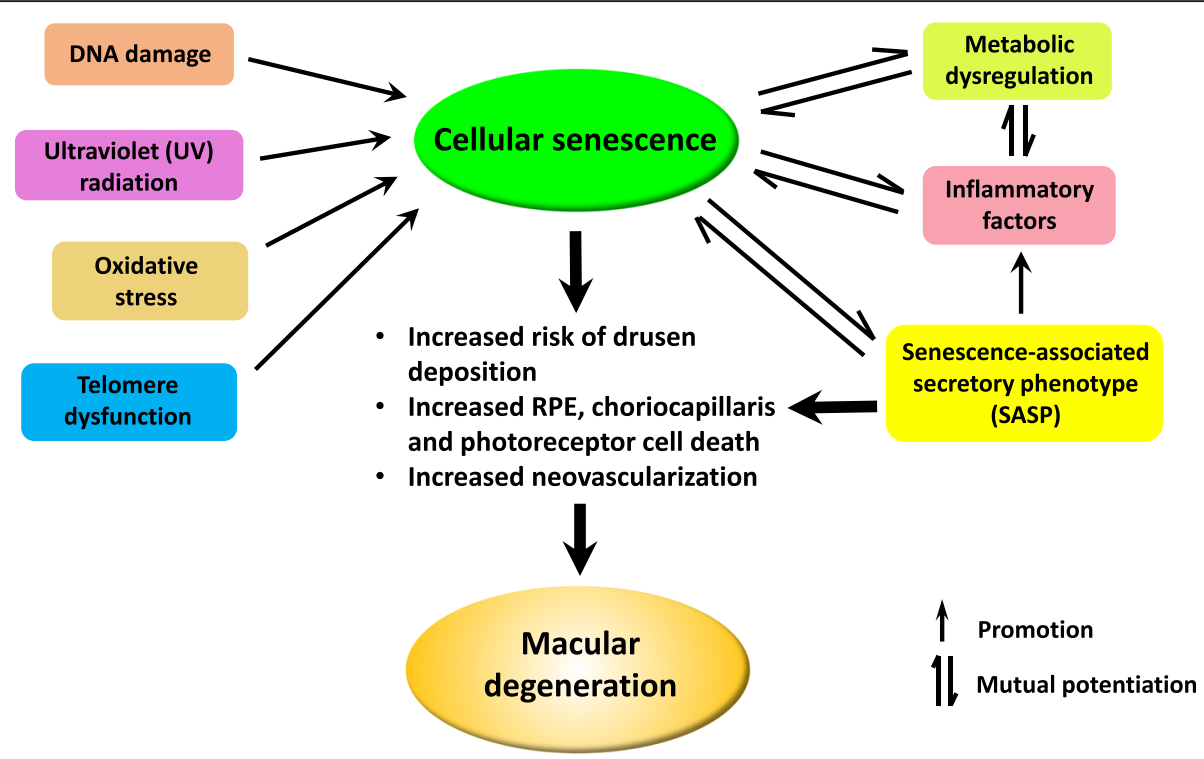

Fig. 1 Etiology and consequences of cellular senescence contributing to AMD. Cellular senescence is highly relevant to AMD pathogenesis. A variety of factors - telomere dysfunction, oxidative stress, nutrient signals, DNA damage, and inflammatory cytokines — can activate cellular senescence in both mitotic and post-mitotic cells. Senescent cells display altered metabolic function and autophagy activity, as well as a distinctive proinflammatory secretome, which are all interlinked. These processes directly impose a cause-and-effect on one another, further accelerating their progression. The consequences of chronic cellular senescence, such as increased drusen deposition, increased RPE, choriocapillaris and photoreceptor dysfunction and cell loss, and/or neovascularization, ultimately lead to the advanced disease phenotype of macular degeneration

neurons, choroidal endothelial cells, and retinal microglia also demonstrate senescence in association with the retinal aging and/or pathogenesis of AMD [47, 60, 61]. As unveiled in a senescence-accelerated OXYS rat model, the retina exhibits transcriptome changes in genes involved in pathways associated with inflammation, apoptosis, DNA damage, and oxidative stress, and develop pathologic changes akin to human AMD [62]. As one of the central mediators for both RS and SIPS, age-associated damages in nuclear DNA (nDNA) and mitochondrial DNA (mtDNA), alongside a declined capacity of DNA repair, together have strong clinical associations with both atrophic and neovascular AMD [63, 64]. In aggregate, the data purport that enhanced cellular senescence drives disease progression.

\section{Senescence occurs in a variety of retinal cells}

The existence of senescent cells in the human eyes during aging or with AMD is increasingly recognized [23, 65]. The schematic presented in Fig. 2 demonstrates the range of known cell types with associated senescent phenotypes during AMD.

The RPE, besides its role as a barrier cell, is essential for the maintenance of visual cycle and photoreceptor health. In those susceptible to AMD, pathological changes in the RPE frequently occurs prior to the death of rods, followed by cone loss [66]. The functional decline in aging RPE can result in the disruption of the outer blood-retinal barrier (BRB) between the retina and the choroid, which predisposes to drusen deposition and progressive macular damage [47]. Age-dependent accumulation of senescent RPE cells can be detected in human and rhesus monkey eyes, remarkably around the cuticular drusen, displaying alteration in cell morphology and reduced cell density $[58,59]$. RPE cells isolated from human aging or AMD donor eyes further highlight the involvement of senescence in AMD, by its expression of senescence-characteristic gene signature, such as upregulation of $\mathrm{p} 16^{\mathrm{INK} 4 \mathrm{~A}}, \mathrm{p} 21^{\mathrm{CIP} 1}, \mathrm{p} 53$, and bone morphogenetic protein-4 (BMP4) [57, 67, 68]. The epigenetic transcriptome analyses of human AMD-RPE unveiled an association between RPE senescence and the epigenetic dysregulation, such as a differentiation of methylated SKI proto-oncogene, which is a negative regulator of the TGF- $\beta$ pathway [56]. As a consequence, the overactivated TGF- $\beta$ signaling induces a SIPS in RPE cells [69] and facilitates an epithelial-mesenchymal transition (EMT), leading to loss of RPE differentiation and compromised cellular function [70]. We have recently demonstrated that RPE cells deficient in interleukin-1 receptor-associated kinase-M (IRAK-M), a key inhibitor of TLR/IL-1R-mediated inflammation, are more susceptible to oxidative stress-induced senescence, evidenced by elevated SA- $\beta-$ Gal and $\mathrm{p} 21^{\mathrm{CIP} 1}$ expression, increased secretion of SASP proteins HMGB1 and IL-6, and decreased nuclear lamina protein LB1. CRISPR-Cas9 


\section{Normal retina}

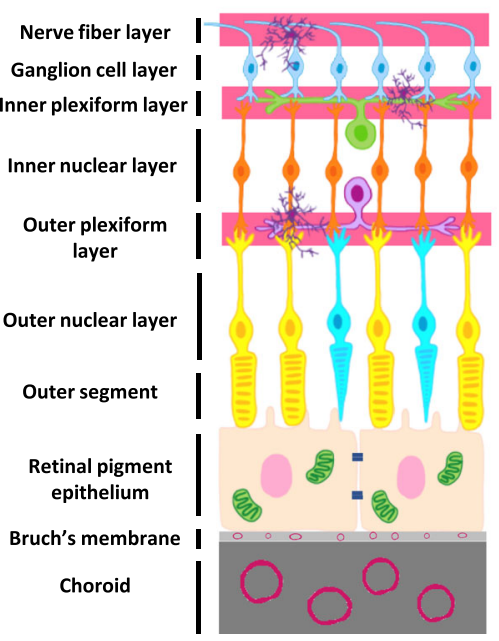

\section{Senescent retina}

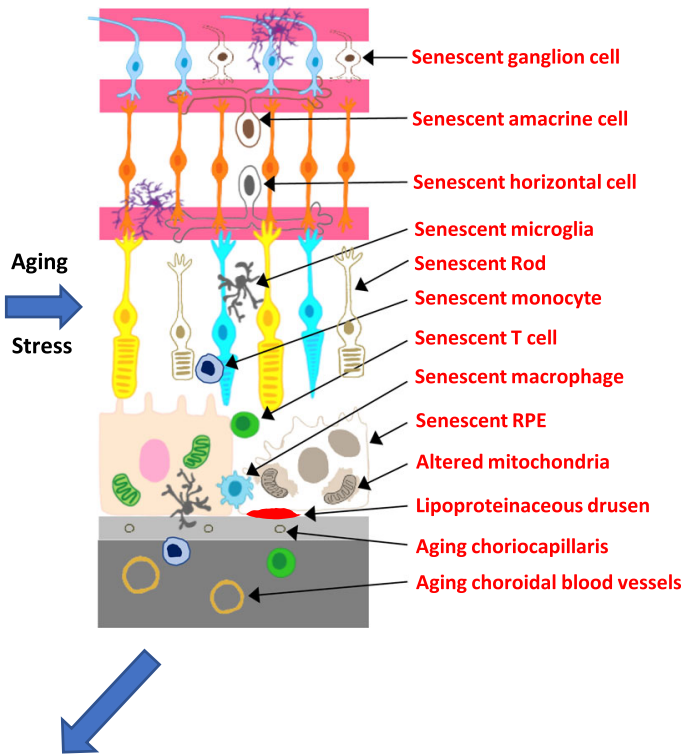

SASP

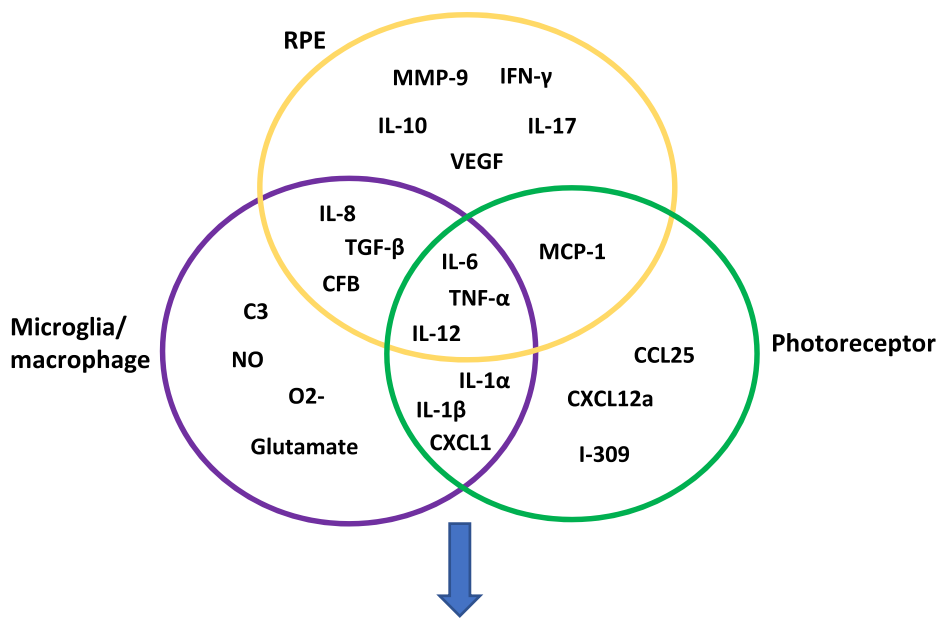

\section{AMD progression}

Fig 2 A schematic diagram of consequences of the senescent retina and induction of SASP during progression of AMD. A healthy retina is an immune-privileged ocular tissue, with active immune regulatory networks and immune cell networks supporting normal retinal cell morphology and function $[1,7]$. In contrast, a "senescent" retina has both damaged cells and impaired function with alterations in microglial morphology, migration, and infiltration of systemic immune cells. Additionally, resident neuronal cells (ganglion cells, horizontal cells, amacrine cells, and photoreceptors), RPEs, and microglia/macrophages, enter a senescent state in the senescent retina. Drusen begin to accumulate between the Bruch's membrane and RPE or in the subretinal space (subretinal drusenoid deposits). The Bruch's membrane thickens and choriocapillaris has a reduced vascular network alongside thinning and diminishing vessels in the aging choroid. Numerous SASP factors, such as IL-6, IL-12, TNF-a, IFN$\gamma$, and IL-8, are released from the senescent retinal cells. ROS, in tandem with damaged DNA, further promote the age-related decline in RPE and photoreceptors resulting in a feedforward cycle of damage. Signaled by the SASP-chemokines released into the tissue environment, immune cells (monocytes, neutrophils, and T cells) extravasate from the blood vessels, infiltrate the retina, and release SASP components, contributing to a chronic inflammation and other AMD-related pathologies

editing of IRAK-M gene activation attenuates SIPS and oxidative damage (Liu et al. unpublished data). Reduced expression of IRAK-M has been linked to excessive inflammation, oxidative stress, obesity, and metabolic syndrome, or when autophagy is inhibited in RPE cells [71, 72]. 
The retina is a neuron-rich tissue that contains more than 60 distinct types of neuronal cells, each playing a specific role in processing visual information [73]. In human neurodegenerative diseases and animal models, neurons of the CNS including cortical, Purkinje, and hippocampal cells, as well as peripheral neurons, display features of cellular senescence and release SASP cytokines [32, 33, 74]. To date, a severe impact of increased senescent neurons has been perceived to exacerbate neurodegeneration in the CNS $[32,65]$. In human aging retina, it has been shown that ganglion, amacrine, horizontal and rod cells, but not Müller or astrocyte neuroglia cells, acquire characteristics of cellular senescence [34]. Interestingly, in contrast to the senescent rods identified in aging retina (not AMD), senescent cones are not evident [34]. This finding could explain, at least in part, why the loss of rod photoreceptors exceeds that of cone photoreceptors during the evolution of human AMD [66]. The observations in the aging retina should be nuanced with data obtained from disease settings. For example, premature senescence of retinal ganglion cells in mice can be induced by experimental ocular hypertension (a model of glaucoma), and an early removal of senescent ganglion cells and their SASP secretion in p16-3MR transgenic mice subjected to ocular hypertension prevents disease progression by rescuing surrounding healthy cells [75]. Whilst there is no evidence of astrocyte senescence in retinal diseases, its contribution to age-related neurodegenerative diseases is recognized both in vitro and in vivo [76].

Choroidal blood vessels provide oxygen supply to the highly metabolically active retina, in particular the photoreceptors. One of the earliest detectable events in AMD is the loss of endothelial cells in the choriocapillaris [77]. Data have shown that aging choroidal endothelial cells in rhesus monkeys exhibit high level of SA$\beta$-Gal and aberrant cytoskeletal contractility, which is mediated by upregulated cytoskeletal Rho activity [60]. These age-related changes in choroidal endothelial cells cause choroidal vascular stiffness (loss of flexibility) and sensitize the choriocapillaris to MAC-induced endothelial death and vascular dysfunction [60]. Senescent retinal vascular endothelial cells are also observed in the aging retina and associated with pathogenesis of retinopathy [34]. It is now recognized that senescence of retinal or choroidal vascular endothelium and, as a consequence, vascular dysfunction play an important role in the progression of different retinal diseases, including AMD [60, 78].

The yolk sac-derived retinal microglia are tissueresident macrophages and the first-line guardian for regional immune surveillance and tissue repair [7]. However, microglia cell senescence may contribute to a persistent inflammation and loss of tissue homeostasis during the development of $\mathrm{AMD}[61,79,80]$. In the aged mouse retina, microglia exhibit significant changes in the expression of key genes controlling inflammatory responses including NF- $\mathrm{KB}, \mathrm{C} 3$, and complement factor $\mathrm{B}$ (CFB). This indicates a role of senescent microglia in promoting complement and immune dysregulation [81]. Moreover, using a transgenic reporter line (heterozygous $\left.C \times 3 c r 1^{+/ g f p}\right)$, senescent retinal microglia in the aged retina are morphologically different from healthy microglia, displaying significantly smaller, less branched dendrites, with slower process motility [61]. These morphological changes downplay their functional capacity to survey and interact with the tissue environment, responding to danger-associated triggers and performing phagocytosis. This perturbation can result in the accumulation of neurotoxic debris or diseased cells that further leads to an exaggerated inflammation and metabolic stress [61, 80]. Therefore, this transformation in phenotype induces disordered microglial distribution in the retina, which may precipitate the formation of AMD.

\section{Senescence in systemic immune cells contributes to retinal degeneration by impaired inflammatory regulation and immune clearance}

Age-related alterations in the tissues, including the aging retina, need to be put in context to changes in an aging immune system [82, 83]. Age-related dysregulation and decline in the immune system are termed "immunosenescence," a process wherein the immune cells display reduced proliferative capacities and altered functions in response to mitogen or antigen stimulation, as frequently observed in aging innate and adaptive immune cells $[84,85]$. Whilst molecular determinants for immunosenescence remain undefined, clinical and experimental evidence reveals remarkable similarities and association between immunosenescence and cellular senescence occurred in immune cells, in particular lymphocytes and macrophages exhibiting common senescence markers such as telomere shortening and increased expression of $\mathrm{p} 16^{\mathrm{INK} 4 \mathrm{~A}}, \mathrm{p} 21^{\mathrm{CIP} 1}, \mathrm{SA}-\beta-\mathrm{Gal}$, proinflammatory cytokines, and cytotoxic molecules [86-89]. It is noteworthy that while senescence is an overarching phenomenon, it can manifest itself in a cellspecific nature. The known hallmarks of immunosenescence include a reduction in peripheral lymphocyte numbers, a relative increase in frequency of memory CD4+ and CD8+ T cells (especially Th17, but reduced Treg inducibility and stability), a chronic, low-grade inflammation (inflammaging) together with subclinical accumulation of proinflammatory factors, and activation/ infiltration of myeloid cells in tissues [5, 82, 90, 91]. The progression of AMD involves active interplays between the innate and adaptive immunity. For example, there is an increase in serum level of $\mathrm{C} 5 \mathrm{a}$ in AMD patients, 
which significantly stimulates the production of IL-22 and IL-17 by T cells [7, 92]. A growing body of evidence has shown that senescence in immune and tissueresident cells collectively contribute to the development of many disorders in the elderly, such as autoimmune diseases, chronic inflammatory diseases, neurodegeneration, and certain cancers $[49,85,93]$.

Innate immune cell types including neutrophils, monocytes/macrophages, and dendritic and natural killer cells have been identified to acquire general senescent characteristics with advanced age, exhibiting dysregulated immune responses and impaired functional capacity [83, 85, 94-96]. Under normal physiological conditions, senescent cells are primarily eliminated by infiltrating leukocytes from the blood or resident immune cells (e.g., microglia), attracted by SASP mediators released from senescent cells. Different immune clearance mechanisms are recognized, such as receptormediated phagocytosis or neutrophil extracellular traps (NETs)-mediated NETosis [83, 97]. However, aged phagocytes such as macrophages and neutrophils demonstrate reduced phagocytotic activity and clearance capacity [50, 83]. Conversely, senescent innate immune cells express increased levels of proinflammatory mediators, which further promotes systemic and local inflammation [7, 72, 82]. Further evidence shows that senescent macrophages induce the production of atypical lipid species within the retina, through miRNAregulated gene transcription $[98,99]$. In aged mice, macrophages isolated express high levels of miRNA-33 and 150, which downregulates the expression of ATPbinding cassette subfamily A member 1 (ABCA1) and stearoyl-CoA desaturase-2 ( $\mathrm{Scd} 2)$ (both are regulators in cellular phospholipid and cholesterol homeostasis), therefore resulting in aberrant lipid metabolism and inflammation in aging retina $[98,99]$. Of translational relevance, human peripheral blood mononuclear cells isolated from AMD patients express increased miRNA150 compared with the cells from age-matched healthy donors [99]. These findings imply that targeting the senescent innate immune cells may protect the senescencedriven disturbance in inflammatory and metabolic pathways during degenerative processes of retina.

Senescent $\mathrm{T}$ cells increase in frequency in the blood of individuals with infections, autoimmune or ageassociated conditions $[100,101]$. Senescent T cells are characterized by a unique secretory profile and loss of costimulatory molecules CD28, CD27, and CD40L [100, 102]. The CD56 + CD28- subpopulation of CD8+ T cells increase in the peripheral blood in both dry and wet subsets of AMD and present increased cytotoxic function [103]. Interestingly, increased numbers of cytotoxic CD8+ $\mathrm{T}$ cells have been ascertained in the macular choroid of human eyes with drusen [104]. Hitherto, there is yet unequivocal evidence for the role of senescent $B$ cells linked to AMD, nor any significant difference in frequency of any B cell subset between AMD patients and age-matched healthy individuals found [105]. Nevertheless, retina-specific autoantibodies were detected in sera and retinas of patients with early AMD, according to some studies [106, 107].

\section{Cellular senescence promotes AMD through a network of molecular cascades}

Oxidative stress instigated by cigarette smoke concentrate (CSC) or hydrogen peroxide $\left(\mathrm{H}_{2} \mathrm{O}_{2}\right)$ can induce SIPS in human RPE cells, characterized by increased ROS and DNA lesions, downregulated $\mathrm{CFH}$, and production of VEGF, IL-6, and IL-8 cytokines [53]. Oxidative stress also stimulates the $\mathrm{p} 16^{\mathrm{INK} 4 \mathrm{~A}} / \mathrm{RB}$ pathway responsible for the onset and maintenance of the senescent state. Cell cycling, especially during G1/S transition, is only permitted by the activation of $\mathrm{RB}$ pathway through the sequential phosphorylation cascade, which is negatively regulated by $\mathrm{p} 16^{\mathrm{INK} 4 \mathrm{~A}}$ that inhibits cyclin A-, cyclin E-, and cyclin D-dependent kinase complexes. Upon adverse or prolonged exposure to oxidative stress conditions, nuclear expression of $\mathrm{p} 16^{\mathrm{INK} 4 \mathrm{~A}}$ is elevated. Binding of $\mathrm{p} 16^{\mathrm{INK} 4 \mathrm{~A}}$ to cyclins leads to dephosphorylated or hypophosphorylated RB. As a result, the subsequent engagement of the E2F transcription factor is impeded, leading to the cessation of cell division and hence senescence [108].

AMD is strongly associated with the single-nucleotide polymorphisms (SNPs) of high-temperature requirement A 1 (Htra1) gene on the chromosome 10q26 AMD locus [1]. The high-risk SNP allele, rs11200638, in the cisregulatory region of Htral, strengthens transcription of the gene. Indeed, increased HTRA1 protein has been found within drusen of both dry and wet AMD [55]. The HTRA family of serine proteases is pivotal in the maintenance of ATP-independent protein quality and cell function under stress conditions, but excessive expression of HTRA1 can induce RPE senescence, extracellular matrix deposition, and polypoidal choroidal vasculopathy associated with AMD [55, 109]. Oxidative stress has been shown to induce the abnormal transcription and production of HTRA1 in human RPE; the exceptional extracellular level of HTRA1 promotes SIPS in RPE cells via activating p38 MAPK in a HTRA1 protease activity-dependent mechanism [55]. Transgenic mice expressing human HTRA1 in RPE exhibit features of AMD, including RPE atrophy and photoreceptor degeneration. HTRA1-overexpressing transgenic mice aged more than 11 months develop occult $\mathrm{CNV}$, partly through the degradation of elastic lamina of Bruch's membrane and an increase of VEGF [110]. 
Endogenous catalysts including telomere erosion, DNA damage, oncogenic activity, or heterochromatin disruption can induce p53-mediated senescence, which is under the regulation of ataxia telangiectasia mutated (ATM) and ataxia telangiectasia and Rad3-related (ATR) kinases for the maintenance of genome integrity. An important downstream molecule of the p53 pathway is $\mathrm{p} 21^{\mathrm{CIP} 1}$, which regulates cellular senescence by mediating p53dependent G1-phase cell cycle arrest [111]. By inhibiting RB phosphorylation, overactivated $\mathrm{p} 21^{\mathrm{CIP} 1}$ blocks its binding to E2F. In addition to its role as the guardian of genome integrity, the p53 regulatory machinery is also intensively involved in ROS generation, autophagy, innate immunity [57], and metabolic pathways, which also contribute to senescent changes in the RPE and SASP, as shown by primary human RPE cell cultures [57].

Interestingly, the nutrient-sensing mTOR signaling pathway also plays a part in cellular senescence [78, 112]. Dysregulated mTORC1 activity is linked with aging, and inhibition of mTOR signaling has been shown to confer extended lifespan and autophagy repression in myriad of animal models [113]. The two different signaling complexes mTORC1 (mTOR/Raptor/G $\beta \mathrm{L}$ ) and mTORC2 (mTOR/Rictor/GßL/SIN1) are both functional in the human eyes. Adenosine monophosphate-activated protein kinase (AMPK) behaves as a metabolic checkpoint that inhibits cellular growth by suppressing the mTORC1 signaling pathway [114]. Treatment with low dose of rapamycin, the specific mTORC1 inhibitor, can inhibit RPE senescence in vitro, evidenced by a decreased percentage of senescence cells and decreased SA- $\beta-$-Gal activity. The mTOR pathway in human RPE cells with high population doubling (PD) number responds more sensitively to exogenous nutrient stimuli such as amino acids than the cells of lower PD number [112]. The retina is recognized as the most metabolically active tissue in the human body, and its high mitochondrial activity and energy demands confer vulnerability to nutritional insults and metabolic dysregulations. In vivo, mTOR inhibition by rapamycin can prevent photoreceptor degeneration induced by RPE stressor exposure [115] or through RPE-specific mTORC1 activation [116]. RNA-Seq analyses on RPE of human AMD eyes revealed an overactivation of the mTOR pathway, hyperphosphorylation of AMPK, and the significant changes in its target pathways. As a result, deranged profiles of metabolites derived from glycophospholipid, lipid, and protein metabolism were detected by metabolomics and lipidomics [24]. This indicates that the mTOR network not only regulates metabolism and aging in response to nutrition and growth factors but is also associated with the acquisition of a senescent phenotype [112]. A caveat is that data to mechanistically link mTOR overactivation with senescence in AMD are lacking.
As a consequence of cellular senescence, SASP also plays a proactive role in the reinforcement of senescence in an autocrine or paracrine manner [23, 27, 117]. SASP can induce a low-grade inflammation, drive cellular senescence of adjacent cells, and display detrimental effects in the tissue microenvironment, associated with the development of age-related pathologies [117]. For example, in an oxygen-induced retinopathy (OIR) model, cellular senescence initially observed in the retinal ganglion neurons propagates to other cell populations of the retina (microglia and vascular endothelial cells), further contributing to the retinopathy [27]. Initiation and maintenance of SASP require the transcription factor, GATA-binding protein 4 (GATA4), which is activated by ATM and ATR (two key protein kinases acting as DNA damage sensors) and actuates NF- $\mathrm{KB}$ signaling pathway [118].

SASP arising from chronic senescence is a master and protracted source of the chronic inflammation typical in aging. It generates SASP-congruent inflammatory mediators detrimental to surrounding cells and tissue [119]. SASP is therefore considered a potential target for treating age-associated diseases, notwithstanding the fact that the composition of SASP differs in accordance with diseases, triggering factors and cell types [65]. To date, mainly in vitro studies of human RPE cells under RS or SIPS conditions (e.g., age-related DAMPs, $\mathrm{A} \beta, \mathrm{CSC}$, or oxidized photoreceptor outer segments) have revealed a panel of RPE-related SASP genes or proteins, including IL-6, IL-8, IL-10, IL-12, IL-17, MCP-1, TNF- $\alpha$, VEGF, MMP-9, IFN- $\gamma$, CFB, and TGF- $\beta$ [53, 120-122] (Fig. 2). Senescent retinal microglia, systemic or infiltrating monocytes/macrophages associated with AMD, have been found to express escalated inflammatory factors IL$1 \alpha$, IL-1 $\beta$, IL-6, IL-8, IL-12, TNF- $\alpha$, C3, CFB, CXCL1, TGF- $\beta$, nitric oxide $(\mathrm{NO})$, superoxide anion $(\mathrm{O} 2-)$, and glutamate $[65,81,123,124]$. Circumstantial evidence from murine models of diabetes-induced retinopathy and defects in lipoprotein receptor indicates inflammatory secretion of IL- $1 \alpha$, IL- $1 \beta$, IL-6, IL-12, TNF- $\alpha$, MCP1, CCL25, CXCL1, CXCL12a, and I-309 by abnormal photoreceptors $[125,126]$. Of note, such proinflammatory mediators derived from altered photoreceptors are all recognized or reported SASP components in other cell types or tissues [127-130]. The involvement of SASP in AMD has clinical manifestation too, as a number of inflammatory cytokines have been uncovered to be elevated either systemically in the sera or locally in the aqueous humor of patients with AMD, particularly IL-6, IL- 8 , IL-12, MCP-1, TNF- $\alpha$, IL- $1 \alpha$, IL- $1 \beta$, and IL17 [82, 123, 131]. Additionally, IL-22 and IL-17, primarily produced by Th17 subset of $\mathrm{T}$ cells, were found to have higher levels in the sera of patients with wet AMD, while increased IL-17 level also detected within AMD lesions [132]. 
Recent data demonstrate that cellular senescence, autophagy dysfunction, and abnormal inflammatory response are interlinked processes that exert a cause-andeffect on each other, a vicious cycle ultimately leading to retinal degeneration. In RPE cells, the interaction between nuclear factor erythroid 2-related factor 2 (Nrf2) and p62 proteins enhances autophagy and improves Nrf2-mediated antioxidant response to dampen inflammation and protect against oxidative stress. Cellular senescence triggers the downregulation of $\mathrm{Nrf} 2$ and weakens the interaction between Nrf2 and p62 [78, 133]. Consequently, the normal function of autophagy is hindered, predisposing the RPE to abnormal inflammation. Dysfunctional autophagy impairs the clearance system, precipitating the formation and accumulation of lipofuscin and drusen. Lipofuscin and drusen deposition accelerate cellular senescence and drive active inflammatory responses, which can further promote autophagy dysfunction $[78,117]$.

Cellular senescence also coordinates structural and functional modifications in multiple cellular organelles. Among them, mitochondria and lysosomes play central roles in metabolic reprogramming and regulation of autophagic clearance the key mechanisms underlining senescence responses $[134,135]$. Not only is mitochondrial alteration a characteristic feature of senescence, but defects in various mitochondrial pathways are noxious insults eliciting entry into senescence. In addition to excessive production of ROS by complex I and III, mitochondrial stress signals can equally arise from mitochondrial dynamics (fission and fusion), electron transport chain, redox state, mitochondrial metabolites, and calcium homeostasis, especially in tissues such as the retina where a healthy mitochondrial turnover is requisite for normal function $[136,137]$. In a healthy eye, the retina functions as a "metabolic ecosystem," where the RPE primarily exploits mitochondrial oxidative phosphorylation (OXPHOS) for energy production and transports glucose to the photoreceptors that mainly rely on aerobic glycolysis (Warburg effect) [138]. In vivo RPE metabolic shift from OXPHOS to glycolysis causes RPE dysfunction and subsequent photoreceptor death [139]. Aged human RPE exhibits depleted reserve capacity of mitochondrial respiration that generates additional ATP in combating stress, leading to increased oxidative stress-induced cell death [140]. Metabolomics analyses of AMD-derived RPE reveal aberrant metabolites of mitochondrial bioenergetics [24]. In senescent cells, including senescent RPE, altered mitochondrial metabolism and membrane potential promote inflammation via assorted pathways such as ROS and ATP production, DAMP (e.g., mtDNA) stimulation, and calcium exchange [141-144].

Mitochondria alongside lysosomes execute metabolic tuning to guide the whole-cell responder program in response to cellular stressors. Recently, a mitochondriallysosomal axis has been proposed as a hinge in the control of cellular senescence [135, 145]. Diminished lysosomal activities and perturbation in its communication with mitochondria are associated with age-related pathologies [134, 135, 145]. Age-associated senescent cells frequently exhibit disturbance in lysosome-mediated autophagy flux, which results in altered cellular proteostasis and accumulation of lipofuscin, an autofluorescent lipid-rich protein aggregate with multiple metabolic origins $[146,147]$. In both atrophic and neovascular AMD, accumulation of RPE intracellular lipofuscins and lysosomal destabilization-induced NLRP3-inflammasome activation occur, inferring lysosomal damage [147, 148]. Lysosomal dysfunction is shown to impact on the mitophagy-regulated mitochondrial turnover, leading to increased mitochondrial mass and superoxide formation, and in turn, altered mitochondrial metabolism and fission aggravate lysosomal impairment and lipofuscinogenesis $[145,149]$. Pertinently, in vitro data suggest that mitochondrial dysfunction plays an initiating role, while lysosomal dysfunction is more directly responsible for autophagy impairment and cellular senescence [150]. Murine models with deficient expression of proteins involved in mitochondrial biogenesis (PGC-1 $\alpha$ ), antioxidant response (NFE2L2), or lysosomal acidification (CRYBA1) demonstrate alleviated RPE mitophagy, dysmorphic photoreceptor changes, and reduced vision $[151,152]$. Not surprisingly, therefore, targeting the mitochondrial-lysosomal axis might constitute new strategies for anti-aging intervention.

\section{The repertoire of senotherapeutic strategies is expanding to fight a spectrum of diseases involving senescence}

Teasing apart the distinct mechanisms of cellular senescence from physiological aging has driven the development of therapeutic approaches that target chronic senescence for the treatment of age-related diseases. The core principles of these strategies are (1) selective clearance of senescent cells by genetic/epigenetic modulation or small compounds to counteract the apoptosisresilience of senescent cells and (2) blockade of the proinflammatory SASP component [119].

Senolytics represent a class of small molecules that are being developed to treat a number of aging-associated pathologies such as diabetes, frailty, cardiovascular disease, and cancers [153]. Research is focused on approaches that exploit the relative resistance to apoptosis against both intrinsic and extrinsic pro-apoptotic signals displayed by senescent cells [119], conferring the prosurvival advantage to persist under stress conditions [154]. Therefore, targeting these pathways may permit selective elimination of senescent cells and limit any 
detrimental side-effects on healthy cells [154]. The first published senolytic was a cocktail of dasatinib, a pantyrosine kinase inhibitor, and quercetin, a naturally occurring flavonoid [155]. When orally administered in combination, dasatinib and quercetin $(\mathrm{D}+\mathrm{Q})$ in murine models were shown to selectively reduce senescent cells in osteoporosis [153]. Two recent clinical trials evaluating $\mathrm{D}+\mathrm{Q}$ further demonstrate protective effects in patients with idiopathic pulmonary fibrosis [156, 157]. Treatment led to a reduction in senescent cell burden [156], evidenced by reduced $\mathrm{p} 16^{\mathrm{INK} 4 \mathrm{~A}}$ and $\mathrm{p} 21^{\mathrm{CIP} 1}$-expressing adipocytes, reduced SA- $\beta$-Gal activity in skin biopsy tissues, and decreased levels of circulating SASP factors including IL- $1 \alpha$, IL-6, and MMP-9 and MMP-12. However, treatment also resulted in unwanted sideeffects, including delayed wound healing, neutrophilia, and thrombocytopenia, highlighting how long-term use of senolytic agents requires careful consideration, particularly when chronic dosing is typically required for treatment of age-related disorders [158].

The p53/p21 ${ }^{\mathrm{CIP} 1}$ axis could also be a promising target for senolytic agents [159]. p53 is the most frequently mutated tumor suppressor gene in human cancer, and its transcriptional activity controls a myriad of biological processes-transient cell cycle arrest, senescence, and apoptosis [160]. In vivo studies show that a modified FOXO4/p53-interfering peptide abates liver chemotoxicity induced by doxorubicin and restores renal function in progeroid and naturally aged mice [159]. $\mathrm{p} 21^{\mathrm{CIP} 1}$, a primary transcriptional target of $\mathrm{p} 53$, is necessary for the survival of senescent cells [161], as demonstrated by the alleviation of liver cell senescence and liver fibrosis in p21 ${ }^{\mathrm{CIP1}}$-deficient mouse models [162]. Further human research in the development of FOXO4 peptide is needed to target the $\mathrm{p} 53 / \mathrm{p} 21^{\mathrm{CIP} 1}$ pro-survival pathway of senescent cells.

Targeted immune cell attack to senescent cells could also show both specificity and efficiency. Senescent cells upregulate the immune recognition cell surface receptor natural killer group 2D (NKG2D), a marker not usually expressed by normal cells. Selective expression of NKG2D on target cells may facilitate immunotherapeutic approaches designed to eliminate these cells [163], and approaches developed for cancer treatment are being investigated for senotherapeutics. For example, inhibiting the immune checkpoint inhibitors such as programmed death 1 (PD-1) is a powerful treatment of cancer and has also been shown to ameliorate symptoms of $\mathrm{AD}$ in murine models [164]. In addition to immuneboosting strategies, chimeric antigen receptor (CAR) $\mathrm{T}$ cells may provide an option to redirect immune responses against senescent cells [165].

Although the elimination of senescent cells appears to be a favorable strategy, it may compromise some beneficial aspects of cellular senescence or even prevent the antitumor protection it affords. Interventions designed to disrupt the proinflammatory microenvironment and suppress SASP secretion provide an alternative route leading to senotherapy $[153,166]$. Contrary to senolytics that selectively eliminate senescent cells, senomorphic agents target proinflammatory signaling networks [49]. Several signaling pathways that converge and activate the NF- $\mathrm{kB}$ and $\mathrm{C} / \mathrm{EBP} \beta$ pathways are amenable to modulation by a broad spectrum of drugs that are already approved by the FDA [167]. For instance, IL- $1 \alpha / \mathrm{IL}-1$ receptor signal transduction is upstream of NF- $\kappa \mathrm{B}$, and the use of neutralizing antibodies against either IL- $1 \alpha$ or its receptor is sufficient to reduce NF- $\kappa B$ transcriptional activity [167]. mTOR inhibitors, such as rapamycin and its analogs, can abolish SASP by reducing the expression of membrane-bound IL- $1 \alpha$ [168]. Clinical trials of the AMPK activator metformin, another potential senomorphic, are currently ongoing or completed to treat osteoporosis and disc degeneration in elderly people, with encouraging success [49].

While limiting the extent of inflammation is potentially promising, using strong anti-inflammatory drugs can itself elicit a range of side effects; hence, targeting specific components of SASP could provide a safer alternative to mitigate the deleterious effects of SASP. Cytokines, such as IL-6, IL-8, and components of SASP, could serve as possible targets. A plethora of monoclonal antibodies are already commercially available, which could potentially be used to neutralize SASP. Approved drugs such as siltuximab or tocilizumab could address the issue of senescence by blocking IL- 6 or its receptor. These drugs have already been launched for the treatment of life-threatening cytokine release syndrome (CRS) as well as IL-6-driven rheumatic and malignant diseases $[169,170]$.

\section{Antagonizing senescence in the eye opens a therapeutic window for AMD}

To address AMD from the perspective of senescence, therapeutic concepts and attempts based on pre-clinical animal models and clinical trials are mainly designed to prevent senescence cell burden, eliminate senescent cells, inhibit harmful SASP secretion, and restore autophagic housekeeping (Fig. 3).

There is evidence indicating that both senescence and SASP directly contribute to cell loss and subsequent accumulation of ROS-producing deposits, together accelerate retinal dysfunction. Therefore, development of senolytic small molecules that selectively target senescent cells are directed to diseases of the aging eye [65]. For example, certain B cell lymphoma 2 (Bcl-2) family proteins are upregulated in senescent cells to evade apoptosis. Selective targeting of $\mathrm{Bcl}-2$ proteins using 


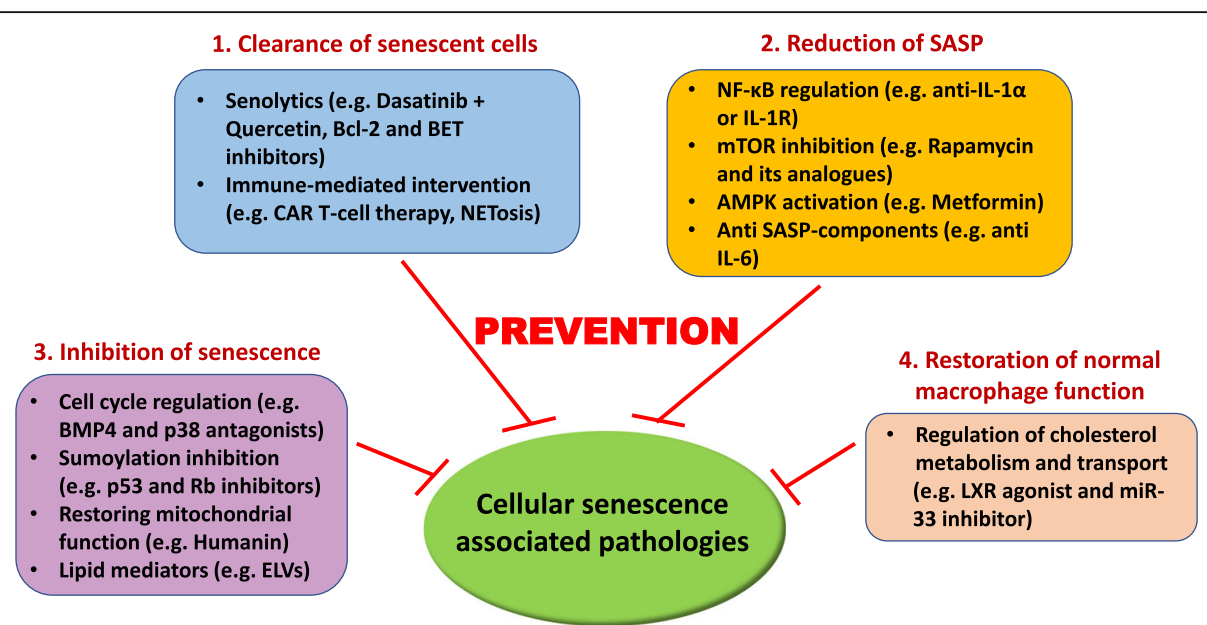

Fig. 3 Prospective senotherapeutic strategies to subvert AMD progression. (1) Selective elimination or modulation of senescent cells through senolytics such as dasatinib + quercetin, inhibitors of BCl-2 or BET proteins, chimeric antigen receptor (CAR) T cells, or by modulating neutrophilinduced NETosis, which can redirect immune responses against senescent cells. (2) Modulation of senescence-related signaling networks (senomorphics) to attenuate SASP through, for example, regulating NF-KB, mTOR, and AMPK pathways, or utilizing monoclonal antibodies against SASP factors, such as IL-6. (3) Inhibition of senescence in the eye using cell cycle regulators, p53/Rb sumoylation inhibitors, mitochondria-derived peptides, or lipid mediators. (4) Restoration of cholesterol homeostasis/flux and normal function of macrophages via liver X receptor (LXR) agonists or miR-33 inhibition, which has proved beneficial in the inhibition of retinal degeneration in vivo

inhibitory drugs UBX1325 and UBX1967, to promote apoptosis in senescent cells, is showing promise for the treatment of age-related ocular diseases including AMD. It will be interesting to see what results come from the recently initiated phase I study to evaluate safety, tolerability, and the pharmacokinetics of intravitreal delivered administration of UBX1325 in patients diagnosed with diabetic macular edema $[65,171]$. Additionally, synthesized small compounds targeting other pro-survival pathways, such as inhibitors of bromo and extraterminal domain (BET) proteins, have been identified via highthroughput screening and show promising therapeutic value as they attenuated RPE cell loss in vitro and protected ganglion cells in vivo [172, 173].

Retinal and choroidal blood vessels, compared with other parts of the eye, have greater remodeling capacity and have served as an effective therapeutic target in neoangiogenic retinal diseases [97, 174]. Elimination of senescent blood vessels may also lead to beneficial vascular remodeling and tissue homeostasis. In the OIR mouse model, age-independent senescence activation in retinal vasculature elicits a senescent secretome and innate immune response characterized by neutrophil recruitment from the blood [97]. The infiltrating neutrophils, releasing neutrophil extracellular traps (NETs), eliminate pathological senescent vasculature through an alternative mechanism of cell death termed as NETosis, thereby promoting retinal vascular regeneration and tissue repair [97]. The findings highlight that the immune cell-mediated clearance of senescent vascular cells ameliorates the severity of pathological neovascularization. More broadly, these immunotherapies via manipulating the sterile inflammation could potentialize a senotherapeutic strategy in other retinal diseases such as AMD [1, 7, 83].

Oxidative stress-induced cellular senescence is another important contributing factor in the development of AMD [39]. Oxidative stress-induced pathological changes in senescent cells highlight other potential targets for senotherapeutics. As a member of TGF- $\beta$ superfamily, BMP4 is the key regulator of RPE morphogenesis and proliferation [67, 175]. Elevated BMP4 expression levels are observed in RPE cells in response to oxidant exposure and at the macular RPE from patients with dry AMD. In primary human RPE cells, overexpression of endogenous BMP4 or the addition of exogenous BMP4 triggers increased expression of cellcycle checkpoint proteins and cellular senescence, via activation of Smad, p38, and $\mathrm{p} 53 / \mathrm{p} 21^{\mathrm{CIP} 1}$, and decreased RB phosphorylation [67]. The premature senescence of RPE, induced by either oxidant exposure or overexpression of BMP4, can be reversed using BMP4 antagonists, such as Chordin-like 1 protein or p38 inhibitor SB203580. Additionally, higher levels of circulating BMP4 is detected in serum samples of wet AMD donors compared to age-matched controls. In collaboration, BMP4 treatment of RPE cells mediates the activity of MMPs, disrupts the barrier integrity of RPE, and induces their migration [176]. The preferential expression of BMP4 in AMD may represent a potential target to selectively protect against oxidative stress and senescence-associated AMD pathology. 
Recent work suggests that sumoylation may represent another novel therapeutic target for the treatment of AMD [177]. Sumoylation is a critical process that regulates retina and RPE aging and refers to a reversible post-translational modification that involves the conjugation of small ubiquitin-like modifier (SUMO) to a target protein. As discussed, p53 and RB are implicated in RPE senescence, and sumoylation modulates the function of p53 and RB by regulation in their transcriptional activity, target-binding, stability, and protein turnover. Sumoylation of chaperon proteins such as Hsp70 can also facilitate RPE senescence through blunting autophagic clearance [178]. The inhibition of sumoylation has been demonstrated to ameliorate proinflammatory cytokine secretion in oxidative stress-induced RPE senescence of aging mice [177].

Restoring mitochondrial homeostasis serves to protect cells against senescence. Within a healthy retinal "metabolic ecosystem," RPE cells primarily exploit mitochondria-dependent OXPHOS for energy production and transport glucose to photoreceptors that mainly rely on aerobic glycolysis [138]. However, aged RPE and RPE derived from AMD patients demonstrate impaired mitochondrial activity that directs a metabolic shift aerobic glycolysis, depleting photoreceptors of energy supply [24]. There are strategies to support mitochondrial function in RPE and counteract the aging process and progress of AMD [179]. Humanin, one of the mtDNA-encoded peptides, protects mitochondria and maintains cell homeostasis and health in experimental models of age-related diseases including tumor and neurodegeneration [180]. In human primary RPE cells, humanin improves mitochondrial biogenesis and activities, restricting oxidative stressinduced senescence [54].

The aggregation of $A \beta$ is recognized as the prominent driver of $\mathrm{AD}$, and in the eye, $\mathrm{A} \beta$ is an important component of drusen in AMD, inducing inflammatory responses and loss of photoreceptors. Elovanoids (ELVs) are a newly identified class of lipid mediators synthesized in RPE and have been shown to protect photoreceptors against oxidative stress [181]. Furthermore, ELVs (particularly ELVs with 32 and 34 carbons) have been demonstrated to counteract oligomeric $A \beta(O A \beta$, a highly cytotoxic form of $A \beta$ species)-induced senescence and inflammatory gene transcription in primary human RPE cells [182].

Aging and senescence are also sensed by retinaresident or infiltrating macrophages. Altered polarization of macrophages and their secretory profiles are involved in the pathologic angiogenesis and formation of a proinflammatory milieu during AMD development $[1,7,8$, 183]. The regulation of macrophage function is under the influence of lipid metabolism and transport [184]. Impaired cholesterol efflux has been associated with reduced drusen scavenge capacity and atypical activation in senescent macrophages [184]. The liver X receptor (LXR), a member of nuclear receptor family of transcription factors, is one of the activators of ABCA1 that regulates cholesterol efflux of macrophages. Interestingly, monocytes from older humans and macrophages from AMD donor eyes showed reduced ABCA1 expression [98]. Macrophage-specific ABCA1-deficient mice exhibit increased intracellular deposition of free cholesterol and abnormal alternative activation of macrophages, promoting accelerated retinal aging and degeneration. Restoration of cholesterol homeostasis using LXR agonist or inhibitor of miR-33, which regulates the expression of genes involved in cellular cholesterol metabolism including $A B C A 1$, reverses the accelerated retina aging in the mice [98].

\section{Conclusions}

The nascent field of senolytics targeting age-related illness including AMD is exciting. Compared to the existing approaches, senotherapeutics target a potential root cause of AMD progression. However, we need to further understand how cells enter senescence and how the beneficial adaptive senescent response shifts to a deleterious chronic senescence. In order to develop therapies to prevent AMD progression, it remains crucial to identify a retinal-specific pattern of senescence and SASP, identify which cells involved in AMD are susceptible and when they enter senescence, and identify an AMDrelated SASP secretion profile. To be successful and sustainable, any development of therapy needs to be specific and reduce off-target or potential oncogenic effects and couple senotherapy with an efficient drug delivery essential to ensure bioavailability and selective targeting, as well as controlled drug release with minimized dosing frequency.

\section{Abbreviations}

ABCA1: ATP-binding cassette subfamily A member 1; AB: Amyloid beta; AD: Alzheimer's disease; AMD: Age-related macular degeneration; AMPK: Adenosine monophosphate-activated protein kinase; AREDS: AgeRelated Eye Disease Study; ATM: Ataxia telangiectasia mutated;

ATP: Adenosine triphosphate; ATR: Ataxia telangiectasia and Rad3-related; BCl-2: B cell lymphoma 2; BET: Bromo and extraterminal domain; BMP4: Bone morphogenetic protein 4; BRB: Blood-retinal barrier; CAR: Chimeric antigen receptor; CCL25: C-C motif chemokine ligand 25; CDK: Cell cycle activators; C/EBP $\beta$ : CCAAT-enhancer-binding protein beta; CFB: Complement factor B; $\mathrm{CFH}$ : Complement factor H; CFI: Complement factor I; CNS: Central nervous system; CNV: Choroidal neovascularization; CRS: Cytokine release syndrome; CRYBA1: Crystallin beta A1; CSC: Cigarette smoke concentrate; CXCL1: CXC chemokine ligand 1; CXCL12a: CXC chemokine ligand 12a; DAMPs: Damageassociated molecular patterns; DPS: Developmentally programmed senescence; DR: Diabetic retinopathy; DSBs: Double-strand breaks; D + Q: Dasatinib and quercetin; ELVs: Elovanoids; EMT: Epithelial-mesenchymal transition; FOXO4: Forkhead box O4; GßL: G protein beta subunit-like; GATA4: GATA binding protein 4; HMGB1: High mobility group box 1; HTRA: High-temperature requirement A; IFN- $ү$ : Interferon gamma; IL1R: Interleukin-1 receptor; IRAK-M: Interleukin-1 receptor-associated kinase-M; LCA: Leber congenital amaurosis; LXR: Liver X receptor; MAPK: Mitogenactivated protein kinase; MAC: Membrane attack complex; MCP-1: Monocyte 
chemoattractant protein-1; MMP-9: Matrix metallopeptidase-9; mTOR: Mammalian target of rapamycin; mTORC1 or 2: Mammalian target of rapamycin complex 1 or 2; NETs: Neutrophil extracellular traps; NFKB: Nuclear factor kappa-light-chain-enhancer of activated B cells; NFE2L2: Nuclear factor, erythroid 2 like 2; NKG2D: Natural killer group 2D; NLRP3: NOD-, LRR-, and pyrin domain-containing protein 3; NO: Nitric oxide; Nrf2: Nuclear factor erythroid 2-related factor 2; OAß: Oligomeric amyloid beta; OIR: Oxygen-induced retinopathy; OSKM: Transcription factors OCT4, SOX2, KLF4, and MYC; OXPHOS: Oxidative phosphorylation; O2-: Superoxide anion; PD: Parkinson's disease; PD: Population doubling; PD-1: Programmed death-1; PGC-1a: Peroxisome proliferator-activated receptor gamma coactivator 1-alpha; RB: Retinoblastoma protein; ROS: Reactive oxygen species; RPE: Retinal pigment epithelium; RS: Replicative senescence; SA- $\beta$ Gal: Senescence-associated beta galactosidase; SAHF: Senescence-associated heterochromatic foci; SASP: Senescence-associated secretory phenotype; Scd2: Stearoyl-CoA desaturase-2; sFlt-1: Soluble fms-like tyrosine kinase-1; SIN1: Stress-activated protein kinase-interacting protein; SIPS: Stress-induced premature senescence; SNPs: Single-nucleotide polymorphisms; SUMO: Small ubiquitin-like modifier; TGF- $\beta$ : Transforming growth factor beta; TLR: Toll-like receptor; TNF-a: Tumor necrosis factor alpha; VEGF: Vascular endothelial growth factor; XLRS: X-linked retinoschisis

\section{Acknowledgements}

This work was supported by a joint grant from the Rosetrees Trust and Stoneygate Trust (grant no. M418-F1).

\section{Authors' contributions}

KSL and SL contributed to the writing of the manuscript and generated the figures. DAC wrote, reviewed, and edited the manuscript. JL and ADD conceptualized and organized the review and wrote and edited the manuscript. All authors approved the final version of the manuscript.

\section{Funding}

This work was supported by a joint grant from the Rosetrees Trust and Stoneygate Trust (grant no. M418-F1).

\section{Availability of data and materials}

All data generated or analyzed during this study are included in this published article.

\section{Ethics approval and consent to participate}

Not applicable.

\section{Consent for publication}

Not applicable.

\section{Competing interests}

The authors declare that they have no competing interests.

\section{Author details}

${ }^{1}$ Bristol Medical School, Translational Health Sciences, University of Bristol, Bristol BS8 1TD, UK. ${ }^{2}$ School of Cellular and Molecular Medicine, University of Bristol, Bristol BS8 1TD, UK. ${ }^{3}$ Institute of Ophthalmology, University College London, London ECIV 9EL, UK. ${ }^{4}$ National Institute for Health Research Biomedical Research Centre, Moorfields Eye Hospital, London EC1V 2QH, UK.

Received: 26 November 2020 Accepted: 15 January 2021 Published online: 22 January 2021

\section{References}

1. Handa JT, Bowes Rickman C, Dick AD, Gorin MB, Miller JW, Toth CA, et al. A systems biology approach towards understanding and treating nonneovascular age-related macular degeneration. Nat Commun. 2019;10(1): 3347.

2. Congdon N, O'Colmain B, Klaver CC, Klein R, Muñoz B, Friedman DS, et al. Causes and prevalence of visual impairment among adults in the United States. Arch Ophthalmol. 2004;122(4):477-85.

3. Scott AW, Bressler NM, Ffolkes S, Wittenborn JS, Jorkasky J. Public attitudes about eye and vision health. JAMA Ophthalmol. 2016;134(10):1111-8.

4. Fritsche LG, Igl W, Bailey JN, Grassmann F, Sengupta S, Bragg-Gresham JL, et al. A large genome-wide association study of age-related macular degeneration highlights contributions of rare and common variants. Nat Genet. 2016;48(2):134-43.

5. Ambati J, Atkinson JP, Gelfand BD. Immunology of age-related macular degeneration. Nat Rev Immunol. 2013;13(6):438-51.

6. Heesterbeek TJ, Lorés-Motta L, Hoyng CB, Lechanteur YTE, den Hollander Al. Risk factors for progression of age-related macular degeneration. Ophthalmic Physiol Opt. 2020;40(2):140-70.

7. Copland DA, Theodoropoulou S, Liu J, Dick AD. A perspective of AMD through the eyes of immunology. Invest Ophthalmol Vis Sci. 2018;59(4): AMD83-92.

8. Liu J, Copland DA, Horie S, Wu WK, Chen M, Xu Y, et al. Myeloid cells expressing VEGF and arginase-1 following uptake of damaged retinal pigment epithelium suggests potential mechanism that drives the onset of choroidal angiogenesis in mice. PLoS One. 2013;8(8):e72935.

9. Fernández-Robredo P, Sancho A, Johnen S, Recalde S, Gama N, Thumann G, et al. Current treatment limitations in age-related macular degeneration and future approaches based on cell therapy and tissue engineering. J Ophthalmol. 2014;2014:510285.

10. Chew EY, Clemons T, SanGiovanni JP, Danis R, Domalpally A, McBee W, et al. The Age-Related Eye Disease Study 2 (AREDS2): study design and baseline characteristics (AREDS2 report number 1). Ophthalmology. 2012; 119(11):2282-9.

11. Carneiro Â, Andrade JP. Nutritional and lifestyle interventions for age-related macular degeneration: a review. Oxid Med Cell Longev. 2017;2017:6469138.

12. Wu J, Sun X. Complement system and age-related macular degeneration: drugs and challenges. Drug Des Devel Ther. 2019;13:2413-25.

13. Taskintuna I, Elsayed ME, Schatz P. Update on clinical trials in dry age-related macular degeneration. Middle East Afr J Ophthalmol. 2016;23(1):13-26.

14. Askou AL, Jakobsen TS, Corydon TJ. Retinal gene therapy: an eye-opener of the 21st century. Gene Ther. 2020.

15. Wu J, Bell OH, Copland DA, Young A, Pooley JR, Maswood R, et al. Gene therapy for glaucoma by ciliary body aquaporin 1 disruption using CRISPRCas9. Mol Ther. 2020;28(3):820-9.

16. Jolly JK, Bridge H, MacLaren RE. Outcome measures used in ocular gene therapy trials: a scoping review of current practice. Front Pharmacol. 2019; 10:1076.

17. Samiy N. Gene therapy for retinal diseases. J Ophthalmic Vis Res. 2014;9(4): 506-9.

18. Guimaraes TAC, Georgiou M, Bainbridge JWB, Michaelides M. Gene therapy for neovascular age-related macular degeneration: rationale, clinical trials and future directions. Br J Ophthalmol. 2020.

19. Heier JS, Kherani S, Desai S, Dugel P, Kaushal S, Cheng SH, et al. Intravitreous injection of AAV2-SFLT01 in patients with advanced neovascular age-related macular degeneration: a phase 1, open-label trial. Lancet. 2017;390(10089):50-61.

20. ClinicalTrials.gov. First in human study to evaluate the safety and efficacy of GT005 administered in subjects with dry AMD 2019 [Available from: https:// clinicaltrials.gov/ct2/show/NCT03846193.

21. ClinicalTrials.gov. Treatment of advanced dry age related macular degeneration with AAVCAGsCD59 2017 [Available from: https://clinicaltrials. gov/ct2/show/NCT03144999.

22. Kaarniranta K, Sinha D, Blasiak J, Kauppinen A, Veréb Z, Salminen A, et al. Autophagy and heterophagy dysregulation leads to retinal pigment epithelium dysfunction and development of age-related macular degeneration. Autophagy. 2013:9(7):973-84.

23. Blasiak J, Piechota M, Pawlowska E, Szatkowska M, Sikora E, Kaarniranta K. Cellular senescence in age-related macular degeneration: can autophagy and DNA damage response play a role? Oxid Med Cell Longev. 2017;2017:5293258.

24. Zhang M, Jiang N, Chu Y, Postnikova O, Varghese R, Horvath A, et al. Dysregulated metabolic pathways in age-related macular degeneration. Sci Rep. 2020;10(1):2464.

25. Weng X, Zhang H, Kan M, Ye J, Liu F, Wang T, et al. Leukocyte telomere length is associated with advanced age-related macular degeneration in the Han Chinese population. Exp Gerontol. 2015;69:36-40.

26. Hyttinen JMT, Kannan R, Felszeghy S, Niittykoski M, Salminen A, Kaarniranta K. The regulation of NFE2L2 (NRF2) signalling and epithelial-tomesenchymal transition in age-related macular degeneration pathology. Int J Mol Sci. 2019;20(22).

27. Oubaha M, Miloudi K, Dejda A, Guber V, Mawambo G, Germain MA, et al. Senescence-associated secretory phenotype contributes to pathological angiogenesis in retinopathy. Sci Transl Med. 2016;8(362):362ra144. 
28. Kirkwood TB. Understanding the odd science of aging. Cell. 2005;120(4): 437-47.

29. HAYFLICK L, MOORHEAD PS. The serial cultivation of human diploid cell strains. Exp Cell Res. 1961;25:585-621.

30. Storer M, Mas A, Robert-Moreno A, Pecoraro M, Ortells MC, Di Giacomo V, et al. Senescence is a developmental mechanism that contributes to embryonic growth and patterning. Cell. 2013;155(5):1119-30.

31. von Kobbe C. Cellular senescence: a view throughout organismal life. Cell Mol Life Sci. 2018;75(19):3553-67.

32. Wengerodt D, Schmeer C, Witte OW, Kretz A. Amitosenescence and pseudomitosenescence: putative new players in the aging process. Cells. 2019;8(12).

33. Moreno-Blas D, Gorostieta-Salas E, Pommer-Alba A, Muciño-Hernández G, Gerónimo-Olvera C, Maciel-Barón LA, et al. Cortical neurons develop a senescence-like phenotype promoted by dysfunctional autophagy. Aging (Albany NY). 2019;11(16):6175-98.

34. López-Luppo M, Catita J, Ramos D, Navarro M, Carretero A, Mendes-Jorge L, et al. Cellular senescence is associated with human retinal microaneurysm formation during aging. Invest Ophthalmol Vis Sci. 2017;58(7):2832-42.

35. Herranz N, Gil J. Mechanisms and functions of cellular senescence. J Clin Invest. 2018;128(4):1238-46.

36. Hoare M, Ito Y, Kang TW, Weekes MP, Matheson NJ, Patten DA, et al. NOTCH1 mediates a switch between two distinct secretomes during senescence. Nat Cell Biol. 2016;18(9):979-92.

37. Sikora E, Arendt T, Bennett M, Narita M. Impact of cellular senescence signature on ageing research. Ageing Res Rev. 2011;10(1):146-52.

38. Herranz N, Gallage S, Mellone M, Wuestefeld T, Klotz S, Hanley CJ, et al. mTOR regulates MAPKAPK2 translation to control the senescence-associated secretory phenotype. Nat Cell Biol. 2015;17(9):1205-17.

39. McHugh D, Gil J. Senescence and aging: causes, consequences, and therapeutic avenues. J Cell Biol. 2018;217(1):65-77.

40. Collado M, Blasco MA, Serrano M. Cellular senescence in cancer and aging Cell. 2007;130(2):223-33.

41. Mosteiro L, Pantoja C, Alcazar N, Marión RM, Chondronasiou D, Rovira M et al. Tissue damage and senescence provide critical signals for cellular reprogramming in vivo. Science. 2016;354(6315).

42. Krizhanovsky V, Yon M, Dickins RA, Hearn S, Simon J, Miething C, et al. Senescence of activated stellate cells limits liver fibrosis. Cell. 2008;134(4):657-67.

43. van Deursen JM. The role of senescent cells in ageing. Nature. 2014; 509(7501):439-46.

44. Xue W, Zender L, Miething C, Dickins RA, Hernando E, Krizhanovsky V, et al. Senescence and tumour clearance is triggered by p53 restoration in murine liver carcinomas. Nature. 2007;445(7128):656-60.

45. López-Otín C, Blasco MA, Partridge L, Serrano M, Kroemer G. The hallmarks of aging. Cell. 2013;153(6):1194-217.

46. Ong SM, Hadadi E, Dang TM, Yeap WH, Tan CT, Ng TP, et al. The proinflammatory phenotype of the human non-classical monocyte subset is attributed to senescence. Cell Death Dis. 2018;9(3):266.

47. Kozlowski MR. RPE cell senescence: a key contributor to age-related macular degeneration. Med Hypotheses. 2012;78(4):505-10.

48. Kim BC, Yoo HJ, Lee HC, Kang KA, Jung SH, Lee HJ, et al. Evaluation of premature senescence and senescence biomarkers in carcinoma cells and xenograft mice exposed to single or fractionated irradiation. Oncol Rep. 2014;31(5):2229-35.

49. Borghesan M, Hoogaars WMH, Varela-Eirin M, Talma N, Demaria M. A senescence-centric view of aging: implications for longevity and disease. Trends Cell Biol. 2020.

50. Pereira Bl, Devine OP, Vukmanovic-Stejic M, Chambers ES, Subramanian $P$, Patel $N$, et al. Senescent cells evade immune clearance via HLA-E-mediated NK and CD8. Nat Commun. 2019;10(1):2387.

51. Childs BG, Durik M, Baker DJ, van Deursen JM. Cellular senescence in aging and age-related disease: from mechanisms to therapy. Nat Med. 2015; 21(12):1424-35.

52. Masaldan S, Belaidi AA, Ayton S, Bush Al. Cellular senescence and iron dyshomeostasis in Alzheimer's disease. Pharmaceuticals (Basel). 2019;12(2).

53. Marazita MC, Dugour A, Marquioni-Ramella MD, Figueroa JM, Suburo AM. Oxidative stress-induced premature senescence dysregulates VEGF and CFH expression in retinal pigment epithelial cells: implications for age-related macular degeneration. Redox Biol. 2016;7:78-87.

54. Sreekumar PG, Ishikawa K, Spee C, Mehta HH, Wan J, Yen K, et al. The mitochondrial-derived peptide humanin protects RPE cells from oxidative stress, senescence, and mitochondrial dysfunction. Investigative Ophthalmology \& Visual Science. 2016;57(3):1238-53.

55. Supanji, Shimomachi M, Hasan MZ, Kawaichi M, Oka C. HtrA1 is induced by oxidative stress and enhances cell senescence through p38 MAPK pathway. Exp Eye Res. 2013;112:79-92.

56. Porter LF, Saptarshi N, Fang Y, Rathi S, den Hollander Al, de Jong EK, et al. Whole-genome methylation profiling of the retinal pigment epithelium of individuals with age-related macular degeneration reveals differential methylation of the SKI, GTF2H4, and TNXB genes. Clin Epigenetics. 2019;11(1):6

57. Chaum E, Winborn CS, Bhattacharya S. Genomic regulation of senescence and innate immunity signaling in the retinal pigment epithelium. Mamm Genome. 2015;26(5-6):210-21.

58. Mishima K, Handa JT, Aotaki-Keen A, Lutty GA, Morse LS, Hjelmeland LM. Senescence-associated beta-galactosidase histochemistry for the primate eye. Invest Ophthalmol Vis Sci. 1999;40(7):1590-3.

59. Datta S, Cano M, Ebrahimi K, Wang L, Handa JT. The impact of oxidative stress and inflammation on RPE degeneration in non-neovascular AMD. Prog Retin Eye Res. 2017;60:201-18.

60. Cabrera AP, Bhaskaran A, Xu J, Yang X, Scott HA, Mohideen U, et al. Senescence increases choroidal endothelial stiffness and susceptibility to complement injury: implications for choriocapillaris loss in AMD. Invest Ophthalmol Vis Sci. 2016;57(14):5910-8.

61. Damani MR, Zhao L, Fontainhas AM, Amaral J, Fariss RN, Wong WT. Agerelated alterations in the dynamic behavior of microglia. Aging Cell. 2011; 10(2):263-76.

62. Kozhevnikova OS, Korbolina EE, Ershov NI, Kolosova NG. Rat retinal transcriptome: effects of aging and AMD-like retinopathy. Cell Cycle. 2013; 12(11):1745-61.

63. Lin $\mathrm{H}$, Xu H, Liang FQ, Liang H, Gupta P, Havey AN, et al. Mitochondrial DNA damage and repair in RPE associated with aging and age-related macular degeneration. Invest Ophthalmol Vis Sci. 2011;52(6):3521-9.

64. Szaflik JP, Janik-Papis K, Synowiec E, Ksiazek D, Zaras M, Wozniak K, et al. DNA damage and repair in age-related macular degeneration. Mutat Res. 2009;669(1-2):169-76.

65. Sreekumar PG, Hinton DR, Kannan R. The emerging role of senescence in ocular disease. Oxid Med Cell Longev. 2020;2020:2583601.

66. Curcio CA, Medeiros NE, Millican CL. Photoreceptor loss in age-related macular degeneration. Invest Ophthalmol Vis Sci. 1996;37(7):1236-49.

67. Zhu D, Wu J, Spee C, Ryan SJ, Hinton DR. BMP4 mediates oxidative stressinduced retinal pigment epithelial cell senescence and is overexpressed in age-related macular degeneration. J Biol Chem. 2009;284(14):9529-39.

68. Ach T, Tolstik E, Messinger JD, Zarubina AV, Heintzmann R, Curcio CA. Lipofuscin redistribution and loss accompanied by cytoskeletal stress in retinal pigment epithelium of eyes with age-related macular degeneration. Invest Ophthalmol Vis Sci. 2015;56(5):3242-52.

69. Yu AL, Fuchshofer R, Kook D, Kampik A, Bloemendal H, Welge-Lüssen U. Subtoxic oxidative stress induces senescence in retinal pigment epithelial cells via TGF-beta release. Invest Ophthalmol Vis Sci. 2009;50(2):926-35.

70. Zhou M, Geathers JS, Grillo SL, Weber SR, Wang W, Zhao Y, et al. Role of epithelial-mesenchymal transition in retinal pigment epithelium dysfunction. Front Cell Dev Biol. 2020;8:501.

71. Hulsmans M, Geeraert B, De Keyzer D, Mertens A, Lannoo M, Vanaudenaerde $B$, et al. Interleukin-1 receptor-associated kinase-3 is a key inhibitor of inflammation in obesity and metabolic syndrome. PLoS One. 2012;7(1):e30414.

72. Liu J, Copland DA, Theodoropoulou S, Chiu HA, Barba MD, Mak KW, et al. Impairing autophagy in retinal pigment epithelium leads to inflammasome activation and enhanced macrophage-mediated angiogenesis. Sci Rep. 2016;6:20639.

73. Masland RH. The neuronal organization of the retina. Neuron. 2012;76(2): 266-80.

74. Jurk D, Wang C, Miwa S, Maddick M, Korolchuk V, Tsolou A, et al. Postmitotic neurons develop a p21-dependent senescence-like phenotype driven by a DNA damage response. Aging Cell. 2012;11(6):996-1004.

75. Rocha LR, Nguyen Huu VA, Palomino La Torre C, Xu Q, Jabari M, Krawczyk $M$, et al. Early removal of senescent cells protects retinal ganglion cells loss in experimental ocular hypertension. Aging Cell. 2020;19(2):e13089.

76. Cohen J, Torres C. Astrocyte senescence: evidence and significance. Aging Cell. 2019;18(3):e12937.

77. Chirco KR, Sohn EH, Stone EM, Tucker BA, Mullins RF. Structural and molecular changes in the aging choroid: implications for age-related macular degeneration. Eye (Lond). 2017;31(1):10-25. 
78. Wang S, Wang X, Cheng Y, Ouyang W, Sang X, Liu J, et al. Autophagy dysfunction, cellular senescence, and abnormal immune-inflammatory responses in AMD: from mechanisms to therapeutic potential. Oxid Med Cell Longev. 2019;2019:3632169.

79. Xu Y, Balasubramaniam B, Copland DA, Liu J, Armitage MJ, Dick AD. Activated adult microglia influence retinal progenitor cell proliferation and differentiation toward recoverin-expressing neuron-like cells in a co-culture model. Graefes Arch Clin Exp Ophthalmol. 2015;253(7):1085-96.

80. Ma W, Coon S, Zhao L, Fariss RN, Wong WT. A2E accumulation influences retinal microglial activation and complement regulation. Neurobiol Aging. 2013;34(3):943-60.

81. Ma W, Cojocaru R, Gotoh N, Gieser L, Villasmil R, Cogliati T, et al. Gene expression changes in aging retinal microglia: relationship to microglial support functions and regulation of activation. Neurobiol Aging. 2013;34(10):2310-21.

82. Nussenblatt RB, Lee RW, Chew E, Wei L, Liu B, Sen HN, et al. Immune responses in age-related macular degeneration and a possible long-term therapeutic strategy for prevention. Am J Ophthalmol. 2014;158(1):5-11.e2.

83. Song P, An J, Zou MH. Immune clearance of senescent cells to combat ageing and chronic diseases. Cells. 2020;9(3).

84. Gruver AL, Hudson LL, Sempowski GD. Immunosenescence of ageing. J Pathol. 2007;211(2):144-56.

85. Costantini $E$, D'Angelo $C$, Reale $M$. The role of immunosenescence in neurodegenerative diseases. Mediators Inflamm. 2018;2018:6039171.

86. Bellon M, Nicot C. Telomere dynamics in immune senescence and exhaustion triggered by chronic viral infection. Viruses. 2017;9(10).

87. Connoy AC, Trader M, High KP. Age-related changes in cell surface and senescence markers in the spleen of DBA/2 mice: a flow cytometric analysis. Exp Gerontol. 2006:41(2):225-9.

88. Yi HS, Kim SY, Kim JT, Lee YS, Moon JS, Kim M, et al. T-cell senescence contributes to abnormal glucose homeostasis in humans and mice. Cell Death Dis. 2019;10(3):249.

89. Childs BG, Baker DJ, Wijshake T, Conover CA, Campisi J, van Deursen JM. Senescent intimal foam cells are deleterious at all stages of atherosclerosis. Science. 2016;354(6311):472-7.

90. Schmitt $V$, Rink $L$, Uciechowski $P$. The Th17/Treg balance is disturbed during aging. Exp Gerontol. 2013;48(12):1379-86.

91. Chougnet CA, Tripathi P, Lages CS, Raynor J, Sholl A, Fink P, et al. A major role for Bim in regulatory T cell homeostasis. J Immunol. 2011;186(1):156-63.

92. Liu B, Wei L, Meyerle C, Tuo J, Sen HN, Li Z, et al. Complement component C5a promotes expression of IL-22 and IL-17 from human T cells and its implication in age-related macular degeneration. J Transl Med. 2011;9:1-12.

93. Fulop T, Larbi A, Dupuis G, Le Page A, Frost EH, Cohen AA, et al. Immunosenescence and inflamm-aging as two sides of the same coin: friends or foes? Front Immunol. 2017;8:1960.

94. Robertson JD, Gale RE, Wynn RF, Dougal M, Linch DC, Testa NG, et al. Dynamics of telomere shortening in neutrophils and T lymphocytes during ageing and the relationship to skewed $X$ chromosome inactivation patterns. Br J Haematol. 2000;109(2):272-9.

95. Linton PJ, Thoman ML. Immunosenescence in monocytes, macrophages, and dendritic cells: lessons learned from the lung and heart. Immunol Lett. 2014;162(1 Pt B):290-7.

96. Judge SJ, Murphy WJ, Canter RJ. Characterizing the dysfunctional NK cell: assessing the clinical relevance of exhaustion, anergy, and senescence. Front Cell Infect Microbiol. 2020;10:49.

97. Binet F, Cagnone G, Crespo-Garcia S, Hata M, Neault M, Dejda A, et al. Neutrophil extracellular traps target senescent vasculature for tissue remodeling in retinopathy. Science. 2020;369(6506).

98. Sene A, Khan AA, Cox D, Nakamura RE, Santeford A, Kim BM, et al. Impaired cholesterol efflux in senescent macrophages promotes age-related macular degeneration. Cell Metab. 2013;17(4):549-61.

99. Lin JB, Moolani HV, Sene A, Sidhu R, Kell P, Dong Z, et al. Macrophage microRNA-150 promotes pathological angiogenesis as seen in age-related macular degeneration. JCI Insight. 2018;3(7).

100. Chou JP, Effros RB. T cell replicative senescence in human aging. Curr Pharm Des. 2013;19(9):1680-98.

101. Pangrazzi L, Weinberger B. T cells, aging and senescence. Exp Gerontol. 2020;134:110887

102. Vallejo AN. CD28 extinction in human T cells: altered functions and the program of T-cell senescence. Immunol Rev. 2005;205:158-69.

103. Faber C, Singh A, Krüger Falk M, Juel HB, Sørensen TL, Nissen MH. Agerelated macular degeneration is associated with increased proportion of CD56(+) T cells in peripheral blood. Ophthalmology. 2013;120(11):2310-6.
104. Ezzat MK, Hann CR, Vuk-Pavlovic S, Pulido JS. Immune cells in the human choroid. Br J Ophthalmol. 2008;92(7):976-80.

105. Hector SM, Sørensen TL. Circulating monocytes and B-lymphocytes in neovascular age-related macular degeneration. Clin Ophthalmol. 2017:11:179-84.

106. Patel N, Ohbayashi M, Nugent AK, Ramchand K, Toda M, Chau KY, et al. Circulating anti-retinal antibodies as immune markers in age-related macular degeneration. Immunology. 2005;115(3):422-30.

107. Cherepanoff S, Mitchell P, Wang JJ, Gillies MC. Retinal autoantibody profile in early age-related macular degeneration: preliminary findings from the Blue Mountains Eye Study. Clin Exp Ophthalmol. 2006;34(6):590-5.

108. Mowla SN, Lam EW, Jat PS. Cellular senescence and aging: the role of BMYB. Aging Cell. 2014;13(5):773-9.

109. Lin MK, Yang J, Hsu CW, Gore A, Bassuk AG, Brown LM, et al. HTRA1, an age-related macular degeneration protease, processes extracellular matrix proteins EFEMP1 and TSP1. Aging Cell. 2018;17(4):e12710.

110. Jones A, Kumar S, Zhang N, Tong Z, Yang JH, Watt C, et al. Increased expression of multifunctional serine protease, HTRA1, in retinal pigment epithelium induces polypoidal choroidal vasculopathy in mice. Proc Natl Acad Sci U S A. 2011;108(35):14578-83.

111. Zhang M, Du Y, Lu R, Shu Y, Zhao W, Li Z, et al. Cholesterol retards senescence in bone marrow mesenchymal stem cells by modulating autophagy and ROS/p53/p21. Oxid Med Cell Longev. 2016;2016:7524308.

112. Chen $Y$, Wang J, Cai J, Sternberg P. Altered mTOR signaling in senescent retinal pigment epithelium. Invest Ophthalmol Vis Sci. 2010;51(10):5314-9.

113. Schmeisser K, Parker JA. Pleiotropic effects of mTOR and autophagy during development and aging. Front Cell Dev Biol. 2019;7:192.

114. Mihaylova MM, Shaw RJ. The AMPK signalling pathway coordinates cell growth, autophagy and metabolism. Nat Cell Biol. 2011;13(9):1016-23.

115. Zhao C, Yasumura D, Li X, Matthes M, Lloyd M, Nielsen G, et al. mTORmediated dedifferentiation of the retinal pigment epithelium initiates photoreceptor degeneration in mice. J Clin Invest. 2011;121(1):369-83.

116. Huang J, Gu S, Chen M, Zhang SJ, Jiang Z, Chen X, et al. Abnormal mTORC1 signaling leads to retinal pigment epithelium degeneration. Theranostics. 2019:9(4):1170-80.

117. Watanabe S, Kawamoto S, Ohtani N, Hara E. Impact of senescenceassociated secretory phenotype and its potential as a therapeutic target for senescence-associated diseases. Cancer Sci. 2017;108(4):563-9.

118. Kang C, Xu Q, Martin TD, Li MZ, Demaria M, Aron L, et al. The DNA damage response induces inflammation and senescence by inhibiting autophagy of GATA4. Science. 2015;349(6255):aaa5612.

119. Ovadya Y, Krizhanovsky V. Strategies targeting cellular senescence. J Clin Invest. 2018;128(4):1247-54.

120. Cao L, Wang H, Wang F, Xu D, Liu F, Liu C. A -induced senescent retina pigment epithelial cells create a proinflammatory microenvironment in AMD. Invest Ophthalmol Vis Sci. 2013;54(5):3738-50.

121. Lazzarini R, Nicolai M, Pirani V, Mariotti C, Di Primio R. Effects of senescent secretory phenotype acquisition on human retinal pigment epithelial stem cells. Aging (Albany NY). 2018;10(11):3173-84.

122. Chen $\mathrm{M}, \mathrm{Xu} \mathrm{H}$. Parainflammation, chronic inflammation, and age-related macular degeneration. J Leukoc Biol. 2015;98(5):713-25.

123. Guillonneau X, Eandi CM, Paques M, Sahel JA, Sapieha P, Sennlaub F. On phagocytes and macular degeneration. Prog Retin Eye Res. 2017;61:98-128.

124. Ramirez Al, de Hoz R, Salobrar-Garcia E, Salazar JJ, Rojas B, Ajoy D, et al. The role of microglia in retinal neurodegeneration: Alzheimer's disease, Parkinson, and glaucoma. Front Aging Neurosci. 2017;9:214.

125. Sun Y, Lin Z, Liu CH, Gong Y, Liegl R, Fredrick TW, et al. Inflammatory signals from photoreceptor modulate pathological retinal angiogenesis via c-Fos. J Exp Med. 2017;214(6):1753-67.

126. Tonade D, Liu H, Palczewski K, Kern TS. Photoreceptor cells produce inflammatory products that contribute to retinal vascular permeability in a mouse model of diabetes. Diabetologia. 2017;60(10):2111-20.

127. Schwab N, Grenier K, Hazrati LN. DNA repair deficiency and senescence in concussed professional athletes involved in contact sports. Acta Neuropathol Commun. 2019;7(1):182.

128. Yamane M, Sato S, Shimizu E, Shibata S, Hayano M, Yaguchi T, et al. Senescence-associated secretory phenotype promotes chronic ocular graftvs-host disease in mice and humans. FASEB J. 2020;34(8):10778-800.

129. Medeiros Tavares Marques JC, Cornélio DA, Nogueira Silbiger V, Ducati Luchessi A, de Souza S, Batistuzzo de Medeiros SR. Identification of new genes associated to senescent and tumorigenic phenotypes in mesenchymal stem cells. Sci Rep. 2017;7(1):17837. 
130. Coppé JP, Desprez PY, Krtolica A, Campisi J. The senescence-associated secretory phenotype: the dark side of tumor suppression. Annu Rev Pathol. 2010;5:99-118.

131. Nassar K, Grisanti S, Elfar E, Lüke J, Lüke M. Serum cytokines as biomarkers for age-related macular degeneration. Graefes Arch Clin Exp Ophthalmol. 2015;253(5):699-704.

132. Knickelbein JE, Chan CC, Sen HN, Ferris FL, Nussenblatt RB. Inflammatory mechanisms of age-related macular degeneration. Int Ophthalmol Clin. 2015:55(3):63-78.

133. Kaarniranta K, Tokarz P, Koskela A, Paterno J, Blasiak J. Autophagy regulates death of retinal pigment epithelium cells in age-related macular degeneration. Cell Biol Toxicol. 2017;33(2):113-28.

134. Machado-Oliveira G, Ramos C, Marques ARA, Vieira OV. Cell senescence, multiple organelle dysfunction and atherosclerosis. Cells. 2020;9(10).

135. Park JT, Lee YS, Cho KA, Park SC. Adjustment of the lysosomal-mitochondrial axis for control of cellular senescence. Ageing Res Rev. 2018;47:176-82.

136. Ziegler DV, Wiley CD, Velarde MC. Mitochondrial effectors of cellular senescence: beyond the free radical theory of aging. Aging Cell. 2015;14(1): $1-7$.

137. Yu B, Ma J, Li J, Wang D, Wang Z, Wang S. Mitochondrial phosphatase PGAM5 modulates cellular senescence by regulating mitochondrial dynamics. Nat Commun. 2020;11(1):2549.

138. Kanow MA, Giarmarco MM, Jankowski CS, Tsantilas K, Engel AL, Du J, et al. Biochemical adaptations of the retina and retinal pigment epithelium support a metabolic ecosystem in the vertebrate eye. Elife. 2017;6.

139. Kurihara T, Westenskow PD, Gantner ML, Usui Y, Schultz A, Bravo S, et al. Hypoxia-induced metabolic stress in retinal pigment epithelial cells is sufficient to induce photoreceptor degeneration. Elife. 2016;5.

140. Rohrer B, Bandyopadhyay M, Beeson C. Reduced metabolic capacity in aged primary retinal pigment epithelium (RPE) is correlated with increased susceptibility to oxidative stress. Adv Exp Med Biol. 2016;854:793-8.

141. Wang S, Liu Y, Li C, Wan Q, Yang L, Su Y, et al. Reversed senescence of retinal pigment epithelial cell by coculture with embryonic stem cell via the TGFß and PI3K pathways. Front Cell Dev Biol. 2020;8:588050.

142. Bratic I, Trifunovic A. Mitochondrial energy metabolism and ageing. Biochim Biophys Acta. 2010;1797(6-7):961-7.

143. Léveillard T, Philp NJ, Sennlaub F. Is retinal metabolic dysfunction at the center of the pathogenesis of age-related macular degeneration? Int J Mol Sci. 2019;20(3)

144. Picca A, Lezza AMS, Leeuwenburgh C, Pesce V, Calvani R, Landi F, et al. Fueling inflamm-aging through mitochondrial dysfunction: mechanisms and molecular targets. Int J Mol Sci. 2017;18(5).

145. Plotegher N, Duchen MR. Crosstalk between lysosomes and mitochondria in Parkinson's disease. Front Cell Dev Biol. 2017;5:110.

146. Moreno-García A, Kun A, Calero O, Medina M, Calero M. An overview of the role of lipofuscin in age-related neurodegeneration. Front Neurosci. 2018;12: 464.

147. Terman A, Kurz T, Navratil M, Arriaga EA, Brunk UT. Mitochondrial turnover and aging of long-lived postmitotic cells: the mitochondrial-lysosomal axis theory of aging. Antioxid Redox Signal. 2010;12(4):503-35.

148. Tseng WA, Thein T, Kinnunen K, Lashkari K, Gregory MS, D'Amore PA, et al. NLRP3 inflammasome activation in retinal pigment epithelial cells by lysosomal destabilization: implications for age-related macular degeneration. Invest Ophthalmol Vis Sci. 2013;54(1):110-20

149. König J, Ott C, Hugo M, Jung T, Bulteau AL, Grune T, et al. Mitochondria contribution to lipofuscin formation. Redox Biol. 2017;11:673-81.

150. Tai H, Wang Z, Gong H, Han X, Zhou J, Wang X, et al. Autophagy impairment with lysosomal and mitochondrial dysfunction is an important characteristic of oxidative stress-induced senescence. Autophagy. 2017;13(1): 99-113.

151. Felszeghy S, Viiri J, Paterno JJ, Hyttinen JMT, Koskela A, Chen M, et al. Loss of NRF-2 and PGC-1a genes leads to retinal pigment epithelium damage resembling dry age-related macular degeneration. Redox Biol. 2019;20:1-12.

152. Sinha D, Valapala M, Shang P, Hose S, Grebe R, Lutty GA, et al. Lysosomes: regulators of autophagy in the retinal pigmented epithelium. Exp Eye Res. 2016:144:46-53.

153. Farr JN, Xu M, Weivoda MM, Monroe DG, Fraser DG, Onken JL, et al. Targeting cellular senescence prevents age-related bone loss in mice. Nat Med. 2017;23(9):1072-9.

154. Kirkland JL, Tchkonia T. Cellular senescence: a translational perspective. EBioMedicine. 2017;21:21-8.
155. Zhu Y, Tchkonia T, Pirtskhalava T, Gower AC, Ding H, Giorgadze N, et al. The Achilles' heel of senescent cells: from transcriptome to senolytic drugs. Aging Cell. 2015;14(4):644-58.

156. Hickson LJ, Langhi Prata LGP, Bobart SA, Evans TK, Giorgadze N, Hashmi SK, et al. Senolytics decrease senescent cells in humans: preliminary report from a clinical trial of dasatinib plus quercetin in individuals with diabetic kidney disease. EBioMedicine. 2019;47:446-56.

157. Justice JN, Nambiar AM, Tchkonia T, LeBrasseur NK, Pascual R, Hashmi SK, et al. Senolytics in idiopathic pulmonary fibrosis: results from a first-inhuman, open-label, pilot study. EBioMedicine. 2019;40:554-63.

158. Zhu Y, Doornebal EJ, Pirtskhalava T, Giorgadze N, Wentworth M, FuhrmannStroissnigg $\mathrm{H}$, et al. New agents that target senescent cells: the flavone, fisetin, and the BCL-X. Aging (Albany NY). 2017:9(3):955-63.

159. Baar MP, Brandt RMC, Putavet DA, Klein JDD, Derks KWJ, Bourgeois BRM, et al. Targeted apoptosis of senescent cells restores tissue homeostasis in response to chemotoxicity and aging. Cell. 2017;169(1):132-47.e16.

160. Kastenhuber ER, Lowe SW. Putting p53 in context. Cell. 2017;170(6):1062-78.

161. Yosef R, Pilpel N, Tokarsky-Amiel R, Biran A, Ovadya Y, Cohen S, et al. Directed elimination of senescent cells by inhibition of BCL-W and BCL-XL. Nat Commun. 2016;7:11190.

162. Yosef R, Pilpel N, Papismadov N, Gal H, Ovadya Y, Vadai E, et al. p21 maintains senescent cell viability under persistent DNA damage response by restraining JNK and caspase signaling. EMBO J. 2017;36(15):2280-95.

163. Sagiv A, Burton DG, Moshayev Z, Vadai E, Wensveen F, Ben-Dor S, et al. NKG2D ligands mediate immunosurveillance of senescent cells. Aging (Albany NY). 2016;8(2):328-44.

164. Baruch K, Deczkowska A, Rosenzweig N, Tsitsou-Kampeli A, Sharif AM, Matcovitch-Natan O, et al. PD-1 immune checkpoint blockade reduces pathology and improves memory in mouse models of Alzheimer's disease. Nat Med. 2016:22(2):135-7.

165. Grupp SA, Kalos M, Barrett D, Aplenc R, Porter DL, Rheingold SR, et al. Chimeric antigen receptor-modified T cells for acute lymphoid leukemia. N Engl J Med. 2013;368(16):1509-18.

166. Chinta SJ, Woods G, Demaria M, Rane A, Zou Y, McQuade A, et al. Cellular senescence is induced by the environmental neurotoxin paraquat and contributes to neuropathology linked to Parkinson's disease. Cell Rep. 2018; 22(4):930-40.

167. Salminen A, Kauppinen A, Kaarniranta K. Emerging role of NF-KB signaling in the induction of senescence-associated secretory phenotype (SASP). Cell Signal. 2012;24(4):835-45.

168. Laberge RM, Sun Y, Orjalo AV, Patil CK, Freund A, Zhou L, et al. MTOR regulates the pro-tumorigenic senescence-associated secretory phenotype by promoting IL1A translation. Nat Cell Biol. 2015;17(8):1049-61.

169. van Rhee F, Wong RS, Munshi N, Rossi JF, Ke XY, Fosså A, et al. Siltuximab for multicentric Castleman's disease: a randomised, double-blind, placebocontrolled trial. Lancet Oncol. 2014;15(9):966-74

170. Chen F, Teachey DT, Pequignot E, Frey N, Porter D, Maude SL, et al. Measuring IL-6 and sIL-6R in serum from patients treated with tocilizumab and/or siltuximab following CAR T cell therapy. J Immunol Methods. 2016; 434:1-8.

171. ClinicalTrials.gov. Safety and tolerability study of UBX1325 in patients with diabetic macular edema 2020 [Available from: https://clinicaltrials.gov/ct2/ show/NCT04537884

172. Wakita M, Takahashi A, Sano O, Loo TM, Imai Y, Narukawa M, et al. A BET family protein degrader provokes senolysis by targeting NHEJ and autophagy in senescent cells. Nat Commun. 2020;11(1):1935.

173. Li J, Zhao L, Urabe G, Fu Y, Guo LW. Epigenetic intervention with a BET inhibitor ameliorates acute retinal ganglion cell death in mice. Mol Vis. 2017:23:149-59.

174. Penn JS, Madan A, Caldwell RB, Bartoli M, Caldwell RW, Hartnett ME. Vascular endothelial growth factor in eye disease. Prog Retin Eye Res. 2008; 27(4):331-71.

175. Xu J, Zhu D, He S, Spee C, Ryan SJ, Hinton DR. Transcriptional regulation of bone morphogenetic protein 4 by tumor necrosis factor and its relationship with age-related macular degeneration. FASEB J. 2011;25(7):2221-33.

176. Ibrahim AS, Hussein K, Wang F, Wan M, Saad N, Essa M, et al. Bone morphogenetic protein (BMP)4 but not BMP2 disrupts the barrier integrity of retinal pigment epithelia and induces their migration: a potential role in neovascular age-related macular degeneration. J Clin Med. 2020;9(7).

177. Sun Q, Qing W, Qi R, Zou M, Gong L, Liu Y, et al. Inhibition of sumoylation alleviates oxidative stress-induced retinal pigment epithelial cell senescence 
and represses proinflammatory gene expression. Curr Mol Med. 2018;18(9): 575-83.

178. Campello L, Esteve-Rudd J, Cuenca N, Martín-Nieto J. The ubiquitinproteasome system in retinal health and disease. Mol Neurobiol. 2013;47(2): 790-810.

179. Ebeling MC, Polanco JR, Qu J, Tu C, Montezuma SR, Ferrington DA. Improving retinal mitochondrial function as a treatment for age-related macular degeneration. Redox Biol. 2020;34:101552.

180. Gong Z, Tas E, Muzumdar R. Humanin and age-related diseases: a new link? Front Endocrinol (Lausanne). 2014;5:210.

181. Jun B, Mukherjee PK, Asatryan A, Kautzmann MA, Heap J, Gordon WC, et al. Elovanoids are novel cell-specific lipid mediators necessary for neuroprotective signaling for photoreceptor cell integrity. Sci Rep. 2017;7(1): 5279.

182. Do KV, Kautzmann MI, Jun B, Gordon WC, Nshimiyimana R, Yang R, et al. Elovanoids counteract oligomeric $\beta$-amyloid-induced gene expression and protect photoreceptors. Proc Natl Acad Sci U S A. 2019;116(48):24317-25.

183. Theodoropoulou S, Copland DA, Liu J, Wu J, Gardner PJ, Ozaki E, et al. Interleukin-33 regulates tissue remodelling and inhibits angiogenesis in the eye. J Pathol. 2017;241(1):45-56.

184. Remmerie A, Scott CL. Macrophages and lipid metabolism. Cell Immunol. 2018:330:27-42

\section{Publisher's Note}

Springer Nature remains neutral with regard to jurisdictional claims in published maps and institutional affiliations.

Ready to submit your research? Choose BMC and benefit from:

- fast, convenient online submission

- thorough peer review by experienced researchers in your field

- rapid publication on acceptance

- support for research data, including large and complex data types

- gold Open Access which fosters wider collaboration and increased citations

- maximum visibility for your research: over $100 \mathrm{M}$ website views per year

At BMC, research is always in progress.

Learn more biomedcentral.com/submissions 